\title{
Etiological associations of Cerebral Venous Sinus Thrombosis (CVT) among Sudanese patients in Khartoum state Neurological Centers, Sudan, 2020
}

\author{
Mohamed Malekaldar \\ Omdurman Teaching Hospital
}

Abbasher Hussien

University of Khartoum, Faculty of Medicine

Khabab Abbasher Hussien Mohamed Ahmed ( $\sim$ khabab9722@gmail.com )

University of Khartoum, Faculty of Medicine https://orcid.org/0000-0003-4608-5321

Yassin Abdalla

Omdurman Islamic University, Faculty of Medicine

\section{Research Article}

Keywords: Cerebral venous sinus thrombosis, CVT, Stroke, Etiology of cerebral venous thrombosis

Posted Date: May 17th, 2021

DOI: https://doi.org/10.21203/rs.3.rs-530219/v1

License: @ (i) This work is licensed under a Creative Commons Attribution 4.0 International License.

Read Full License 


\section{Abstract \\ Background}

As cerebral venous sinus thrombosis is common in our country and it carries a high risk of morbidity and mortality if it is not detected and treated early. The common aetiological associations of CVST are postpartum, pregnancy and oral contraceptive pills.

\section{Objectives}

To study the etiological association of CVST among Sudanese patients in Khartoum state in neurological centers.

\section{Methodology}

This is a descriptive prospective hospital based study was conducted on CVST patients in four neurological centers in Khartoum state in the period from March to October 2020.

\section{Results}

Sixty patients were studied for etiological association of CVST using standardized questionnaire including medical history, clinical examination, investigation and treatment. The most common etiological association were pregnancy in 15(25\%) OCP in 11(18.3) and being in the post-partum period in 23(38.3\%).

\section{Recommendation}

Cerebral venous sinus thrombosis is a treatable condition and has good outcome. Early detection of patients and performing suitable work up including thrombophilia and connective tissue disease screening is essential.

\section{Conclusion}

Post-partum, pregnancy and oral contraceptive pills were the most common etiological associations of cerebral venous sinus thrombosis compared with other populations.

\section{Introduction}


Cerebral Venous Sinus Thrombosis has high morbidity and mortality in our country. There are few studies concerning CVST, therefore, this study aimed to investigate the etiological associations of CVST in our group of adult Sudanese patients with CVST.

Cerebral venous sinus thrombosis (CVST) is an infrequent cause of stroke, representing $0.5 \%$ of all cerebrovascular events on a global scale [1]. Despite the disease being uncommon in a global perspective, CVST is of particular interest in low income countries which bear the heaviest burden of the disease. CVST is particularly common in young and middle-aged groups, with females demonstrating the highest frequency of occurrence. This extremely skewed gender distribution is likely a product of the sexspecific risk factors of oral contraceptives, pregnancy and puerperium [2].

Predisposing causes of CVT are multiple, with at least one risk factor implicated in $85 \%$ of affected adults. Furthermore, multifactorial causes have been identified in a substantial number of cases. A small proportion of cases remain idiopathic [3] [4]. Prothrombotic states, either genetically imposed or acquired, represent a large component of the etiology. Deficiencies of Antithrombin III, protein C, and protein S along with factor $\mathrm{V}$ Leiden mutation (resistance to activated protein $\mathrm{C}$ ) among genetic thrombophilias, are well established predisposing conditions. Women who take oral contraceptives and have the prothrombin G20210 mutation may be at particularly high risk for CVST [5][6]. Acquired prothrombotic states such as antiphospholipid antibodies have also been implicated in the development of CVST. Malignancy, systemic inflammatory conditions, haematological conditions, dehydration and infections among others precipitants, can exacerbate hypercoagulability and provoke CVT in susceptible patients. Additionally, manoeuvres that may directly or indirectly alter the cerebral venous circulation have also been identified as risk factors of CVST in hospital settings [7] [8].

The onset of CVST is subacute in the vast majority of cases, in contrast to the acute presentation of arterial stroke. There is also a more progressive evolution of the clinical presentation in patients with CVST. Thrombosis of the cerebral veins may cause focal deficits due to local effects of venous obstruction, but also generalized effects as a result of increased cerebrospinal fluid (CSF) pressure. Headache is the most common and, usually, the first symptom of CVT [3]. The extensive and highly variable spectrum of clinical presentation makes it particularly difficult for the diagnosis of CSVT, and a high index of clinical suspicion is required for detecting affected individuals. Neuroimaging studies are therefore of paramount importance, as venous sinus occlusion is readily visualized using magnetic resonance (MR) or CT venography or conventional x-ray angiography. Guidelines from both the European Stroke Organization and the American Heart Association outlined anticoagulation with a therapeutic dose of heparin as the primary treatment for CVT, regardless of the presence of intracranial hemorrhage (ICH) at baseline [9][10]. Longer-term Oral anticoagulation therapy with vitamin $\mathrm{K}$ antagonists (VKAs) follows the acute treatment, although the optimal duration of antithrombotic therapy has not been established by randomized controlled studies. Anticoagulation is often continued indefinitely if thrombophilia is diagnosed. Direct oral anticoagulants (DOACs) have not been validated in the treatment of CVT. Similarly, surgical approaches to CVT have no proven benefit; mechanical thrombectomy is therefore utilized as a lifesaving measure in selected refractory cases. 
The natural course of CVST differs significantly from the various subtypes of arterial stroke, with the overall outcome being affected by the patient's age, anatomical location of the involved sinus and associated cerebral veins, and the involvement of the cerebral parenchyma. Around $4 \%$ mortality exists in the acute phase, usually due to complications of cerebral edema, coma, and herniation [14]. Patients have an increased risk of developing sinovenous thrombosis recurrence or other forms of venous thromboembolism (VTE) in about one-third of cases [11].

In recent years, the introduction of new diagnostic techniques has made possible a considerable improvement in the management of CVT; however, some gray areas and uncertain aspects still exist and will probably offer the possibility of future progress. The main points concern the etiologic factors, the clinical indicators for an early diagnosis, the imaging techniques and the close relation and interdependence between therapy and prognosis.

In the field of etiology, many important conclusions have been reached, but some discrepancies between the various studies are evident. In particular, the importance of OCs, although relevant in all studies, varies considerably in relation to both methodological issues and the composition of the population considered. With respect to causative factors, the populations considered cannot be compared as they differ from a demographic and cultural point of view; in particular, some cultures reject $\mathrm{OC}$ for birth control. This observation highlights the importance of culture and ethnicity in the design and interpretation of epidemiological studies and clinical trials, a factor often overlooked and not considered fully. It should be considered that a large portion of CVT takes place in African and Asian countries, where obstetric causes are responsible for up to $30 \%$ of the incidence. The relevance of cultural factors will probably increase in the near future as a consequence of the rapid demographic changes induced by migration flows. The second consequence of the important role of $\mathrm{OC}$ and of pregnancy-puerperium as causative factors is that it fully qualified CVT as a gender-related neurological disorder.

With respect to the clinical features, a clear distinction between presenting symptoms and symptoms developing along the course of the disease should always be made. The signs and symptoms of CVT are highly variable and often change in relation to the stage of the disease. Analysis of the scientific literature demonstrates a paucity of studies that specifically assess the clinical presentation and temporal evolution of symptoms. Headache has been clearly identified as the most frequent presenting symptom, but so far no specific features have been identified. Since headache is one of the most frequent conditions observed in the emergency setting, the identification of patients with CVT and headache as an isolated symptom is a challenging task. New case-control studies specifically designed to assess the problems of the clinical presentation and of the differential diagnosis of CVT, with a special attention for headache are, therefore, urgently needed.

New imaging techniques have considerably eased the diagnosis of CVT; the current gold standard is MRI of the brain with venous MRI angiography. However, these techniques still have a low sensitivity in the case of isolated thrombosis of a cortical vein or of early sinus thrombosis; in these instances conventional angiography is needed. The choice of the most appropriate and accurate examination must 
be based on the clinical features: this consideration again highlights the necessity of reliable clinical indicators for an early diagnosis, which may also guide the radiological diagnostic work-up.

The best available therapy for CVT is currently early anticoagulation with heparin. Although no clear differences between unfractionated and low-molecular-weight heparin have been demonstrated, we prefer unfractionated heparin because of the easier reversal of anticoagulation in case of hemorrhagic complications. An interesting alternative in the acute setting is offered by local thrombolysis, but its use is currently not supported by scientific evidence and should be considered as experimental. This treatment, however, could be considered in patients who worsen despite anticoagulation and who are comatose at presentation; the presence of intracerebral hemorrhage should raise more caution as it is probably linked with an increased risk of bleeding. Anticoagulation or thrombolysis should be attempted as soon as possible, as both trials and clinical experience have shown the importance of early treatment in improving the course of the disease. In fact, any delay in the diagnosis and treatment of CVT can have dramatic clinical consequences: venous thrombosis is a time-dependent process whose progress may be stopped by anticoagulants.

Overall, the best clinical management of CVT depends on the optimization of three main steps: the identification of clinical indicators that give rise to a diagnostic hypothesis in the early stage of the disease, the choice of the best radiologic exams to support this suspicion and the early institution of the appropriate treatment.

\subsection{Literature Review}

\subsubsection{Anatomy of the Venous System}

Venous drainage of the brain can be essentially divided into two main districts: a superficial system that receives blood from the brain convexity (mainly from the cerebral cortex); and a deep system, which instead drains the deep white matter and the grain nuclei. The superficial veins drive blood from the frontal and parietal lobes into the superior sagittal sinus, while blood from the temporal and occipital lobes is drained by the left and right transverse sinuses. The deep cerebral veins, on the other hand, drain blood into the straight sinus through the Galen vein or into the transverse sinuses. The venous circulation of the neural structure in the posterior region, including the brainstem and cerebellum, have a more variable and inconstant anatomy; however, the veins of this region ultimately end in the transverse sinuses. Finally, the venous blood from the anteroinferior areas of the brain (inferior surface of the frontal lobes) and from the face is collected in the cavernous sinuses, and from there is driven to the transverse sinuses through the petrous sinuses. The superior sagittal, transverse and straight sinuses are connected in the confluence of sinuses in the posterior fossa; therefore, thrombotic processes affecting this area can impair the venous drainage of most of the brain and are, thus, responsible for dramatic and often fatal clinical syndromes. Further anastomotic connections are often present: the superficial system is connected with the deep system through the vein of Trabant, while the superior sagittal and transverse sinuses are in communication through the vein of Labbè. These pathways may provide some collateral flow in case of venous occlusions, explaining the mild clinical conditions observed in many patients. 
Most of the venous blood of the brain is eventually collected into the transverse sinuses, which continue into the sigmoid sinuses and deep jugular veins; one of the later sinuses is often prevalent and conveys more blood flow. A minority of venous blood is also drained through anastomotic connections with the vertebral plexus.

\subsubsection{Pathophysiology of Cerebral Venous Thrombosis}

The two main pathogenic mechanisms of cerebral venous thrombosis (CVT) are intracranial hypertension and parenchymal ischemia; these two aspects often coexist but are responsible for distinct clinical symptoms. The consequences of CVT depend on the prevalence of the former or the latter mechanisms, and on the site and extent of the venous occlusion in relation to the anatomical features described previously. In case of a limited sinus occlusion, an effective collateral flow through cortical collaterals or with the deep circulation is often possible. In this case, parenchymal damage is limited to a localized edema without ischemic lesions. If the thrombotic process is more widespread and involves more than one sinus, collateral flow is insufficient to allow venous drainage; the first consequence is a dramatic increase in capillary pressure, leading to leakage of fluids in the extracellular compartment, brain swelling and intracranial hypertension.[1,2] In addition, in cases of thrombosis of a cortical vein, collateral circulation is impossible. In this case, brain ischemia develops rapidly and a venous stroke is invariably present. Venous strokes have peculiar characteristics compared with arterial ones: the degree of edema is usually greater and hemorrhagic complications, ranging from small petechial lesions to a proper hemorrhagic infarction, are much more frequent.[3,4] The higher degree of brain edema is probably due to the presence of a vasogenic component, which is absent in arterial strokes, as demonstrated by MRI techniques.[5,6] The vasogenic component can be rapidly offset when venous drainage is restored, without the development of a permanent parenchymal lesion; this might be the reason why some venous strokes apparently of large size have a more favorable outcome. The prevalence of vasogenic edema has also suggested a possible use of steroids to limit brain swelling, but clinical experience has been disappointing. The high frequency of hemorrhagic complications, the frequent cortical involvement and the severe brain edema are probably responsible for the elevated rate of seizure observed in venous stroke,[7,8] in contrast to arterial stroke; these features are also important for the different diagnosis of cavernous sinus thrombosis.

An important pathogenic mechanism in CVT is the development of intracranial hypertension. Elevation of intracranial pressure may be due to a reduction of liquoral absorption resulting from sinus occlusion or to the mass effect of swollen brain areas. Intracranial hypertension may be mild, usually in patients without parenchymal lesions and with limited clinical features, or may lead to a dramatic worsening of the clinical conditions and to coma. The latter condition is most often observed in patients with large supratentorial lesions with a severe mass effect or in patients with occlusion of vessels of the deep circulation. In fact, in cases of occlusion of an internal cerebral vein or of the straight sinus, the diencephalic structures responsible for awareness are directly injured, leading to early loss of consciousness in these patients. Furthermore, edema of these centrencephalic areas leads rapidly to 
compression of the brainstem, endangering patient survival. Finally, parenchymal, subdural and even subarachnoid hemorrhages have been described as a consequence of venous thrombosis. $[9,10]$

\subsubsection{Causes of CVT}

The main causes of CVT are essentially similar to those of venous occlusion in other regions and may be caused by pathologies that either affect the vessel wall, reducing blood flow, or induce a state of systemic hypercoagulation. The causes of CVT have been recorded in two recent studies. The first was a multicentric prospective record that enrolled 650 patients mainly in Europe and South America, but also with contributions from China, Australia and Canada;[22] the International Study for Cerebral Venous Thrombosis (ISCVT). The study had a prospective design and a median follow-up of 16 months. The second study analyzed a total of 232 patients from the USA, 157 by retrospective chart review and 75 by prospective enrollment; only 182 patients, however, fulfilled the predefined diagnostic criteria and were included in the study.[12]

Before discussing the different causes identified, some preliminary methodological considerations are needed. First of all, the study of Wasay et al. included a majority of patients identified with retrospective analysis: this feature may be responsible for the high rate of patients labeled as 'unidentified cause' (43 vs $12 \%$ of the ISCVT), and to the underestimation of same causative factors, such as oral contraceptive (OC) use, which is present in only $5 \%$ of patients compared with $54 \%$ of the ISCVT. Furthermore, while more than one causative factor was allowed in the ISCVT, only one cause was attributed to each patient in the study by Wasay and some risk factors were not tested in all patients. However, the presence of multiple risk factors is very likely and is probably a better description of the actual clinical reality. As a result of these differences, direct comparison of the two studies is difficult as far as etiology is concerned and, for this reason, we did not pool the data from these two sources. Also, the earlier cohort studied by Ameri and Bousser reported a much lower rate of contraceptive use, but as the patients were recruited retrospectively it may be influenced by the same bias.[13] Finally, in our own group of 44 patients, we found a similar distribution as the ISCVT.[14] The causes of CVT ascertained in the two larger studies and in the two retrospective groups are reported in.

Despite these methodological problems, however, some conclusions can indeed be drawn. First of all, the main cause of CVT is linked to pregnancy or puerperium (6.3 and $13.8 \%$, respectively, in the ISCVT) or to assumption of OCs. The ISCVT also reported a $4.3 \%$ rate of patients assuming hormone-replacement therapy. All of these conditions share the state of hypercoagulation induced by estrogens as the causative factor of CVT. The role of estrogens in determining CVT was indeed first suggested by the rapid increase of the female-to-male ratio of the disease after the widespread use of OCs (465 out of the 625 patients in the ISCVT were females); and has more recently been confirmed in two case-control studies. $[15,16]$ As for peri- and post-partum, the risk has been estimated to be approximately 12 cases for every 100,000 births.[17]

Other causes include inherited or induced states of hypercoagulation; the former are more prevalent and are present in $10-20 \%$ of patients. These include a deficit of proteins $\mathrm{C}$ or S, antithrombin III and 
resistance to factor V. It is important to note that in ISCVT $40 \%$ of patients had more than one risk factor; the most frequent association is a combination of OCs or puerperium-peripartum with an inherited coagulopathy. In particular, prothrombin gene mutation 20210A has been found to be the most frequent genetic alteration in CVT patients and to significantly increase the risk when combined with use of OCs. $[15,18]$ Therefore, the search for causal factors should be extensive in all patients and should always include a screening for coagulopathies; the identification of one factor should never stop the diagnostic work-up. Interestingly, the risk associated with $\mathrm{OC}$ use does not seem to be increased by cigarette smoking, in contrast to arterial stroke. As a matter of fact, a case-control study on 43 young women with CVT whose only risk factor was OC use and 255 healthy OC users did not show any difference in the rate of smokers.[19] This may reflect the different pathogenic mechanism in arterial and venous stroke, but more data from epidemiological and clinical studies in this field are needed. Other causes of hypercoagulation that must always be considered are tumors, systemic infections and acquired hypercoagulation states, which include antiphospholipid antibodies, nephrotic syndrome and hyperhomocysteinemia. A similar mechanism, which involves an increase of blood viscosity, is present in case of polycythemia or leukemia, or of severe anemia or dehydration. The role of severe anemia as a risk factor of CVT has been specifically tested in a prospective study on 120 subjects (odds ratio [OR] = 1.10; 95\% Cl: 1.01-2.22; $p<0.05) .[20]$

Inflammatory conditions may cause CVT by direct damage of vessel walls or by inflammatory hypercoagulative states, including systemic lupus erythematosus, Behçet's disease and rheumatoid arthritis. Also, sarcoidosis and intestinal bowel diseases and vasculitis in the setting of AIDS are thought to cause venous thrombosis by such mechanisms. Local causes instead lead to direct damage of a sinus or cortical vein or to the impairment of local venous circulation. The former mechanism is involved in the case of CNS neoplasms and head trauma or surgery, while the latter is more frequent in the case of brain or dural arteriovenous malformations. Finally, some infectious diseases may spread to the brain sinuses by contiguity and lead to their thrombosis. Such a mechanism is responsible for cases of transverse sinus occlusion in patients with middle ear otitis, or of cavernous sinus syndrome in those with ocular or facial infections. Infectious conditions were among the first causes of CVT in the past, but their incidence was reduced in industrialized countries by the introduction of antibiotics. However, the ISCVT still reports

an $8.2 \%$ rate of middle ear, face or neck infection as causative factors, probably reflecting the persistence of such pathologies in other parts of the world, such as South America or China (only $1 \%$ was reported in the USA study).

\subsubsection{Clinical Features and Diagnosis of CVT}

\section{Clinical Features \& Presenting Syndromes}

The clinical presentation of CVT is highly variable, ranging from cases with mild symptoms and normal neurological examination to others who present with coma and have a severe neurological dysfunction. [21] This variability represents an engaging diagnostic challenge for clinical neurologists and is one of 
the main difficulties in the field of CVT. However, four main clinical syndromes can be clearly identified, although individual patients may shift from one group to another during the course of the disease.

\section{Patients with isolated intracranial hypertension}

Patients with isolated intracranial hypertension have the mildest symptoms and the best prognosis; $22.9 \%$ of patients in the ISCVT and $38 \%$ in the USA study were in this group. Most patients in this group only have a headache,[22] but diplopia secondary to increased intracranial pressure may also be present. When papilledema is also present ( $29 \%$ of patients, peripheral visual loss can also be part of the syndrome. However, since papilledema is not found in many patients, its absence does not rule out a diagnosis of CVT.

\section{Patients with focal neurological signs}

Patients with focal neurological signs may be both negative (deficits), as a result of a focal cortical damage secondary to a venous stroke (over $40 \%$ of patients), or positive, reflecting a focal epileptic activity. Focal seizures were present in $17 \%$ of the patients recruited in the two larger studies available, while seizures with generalization (primary or secondary) were present in $29 \%$ of patients. Overall, seizures were the presenting symptoms in $40 \%$ of patients, a much higher rate than that observed in arterial strokes. Therefore, the presence of seizures in a patient with an ischemic brain lesion should always suggest the possibility of venous thrombosis. Patients who present with seizure should be divided into those with and those without a parenchymal brain lesion, as the former have a higher risk of recurrence. The presence of bilateral neurological signs or the rapid development of contralateral signs, although rare, is highly suggestive of an occlusion of the superior sagittal sinus ( $3 \%$ of patients in the ISCVT and ultrasound studies had this syndrome).

\section{Patients who present with coma or behavioral alterations}

Patients who present with coma or behavioral alterations, such as delirium, amnesia or mutism, are associated with a negative outcome, as it is often the consequence of a thrombotic occlusion of the deep or posterior circulation or of occlusion of multiple sinuses. Also, patients with a large supratentorial ischemic or hemorrhagic lesion causing transtentorial herniation may present with this syndrome. In the ISCVT, $14 \%$ of patients were in this group.

Patients presenting with headache, diplopia secondary to the paresis of a cranial nerve, periorbital swelling \& chemosis

A few patients (1.3\% in ISCVT) present with headache, diplopia secondary to the paresis of a cranial nerve, periorbital swelling and chemosis. This syndrome is nearly pathognomonic of cavernous sinus occlusion. In addition, the timing of onset, as with the presenting clinical features, is variable. In the ISCVT the mode of onset was acute in $37.2 \%$ of cases, subacute in $55 \%$ and chronic in $7.2 \%$.[22] One of the most frequent symptoms of CVT is headache, which is present in over $80 \%$ of patients and is the presenting symptom in nearly $70 \%$.[23] Although the headache is associated with other neurologic signs 
in the majority of patients, it can also by isolated ( $20 \%$ in the ISCVT). Therefore, the identification of headache features associated with CVT could have a high clinical relevance and may be helpful to identify the patients that need to be studied with imaging techniques. For this reason, we studied a group of 49 patients with a diagnosis of CVT and headache and compared them with 90 control patients with headache of another cause.[14] Unfortunately, headache associated with CVT has no specific features, as it can have an acute, subacute or chronic onset, be localized or diffuse and have any severity. The pain can be associated with nausea and vomiting, and can be both continuous or pulsating. When pain is lateralized and pulsating, an erroneous diagnosis of migraine is often made.[24] Moreover, it is worth noting that in as many as $7 \%$ of our patients the pain had a hyperacute onset, mimicking subarachnoid hemorrhage. $[25,26]$ We found a positive correlation between CVT, acute headache onset $(p<0.005)$ and severe headache $(p=0.024)$. These data were confirmed in a small prospective study on 27 subjects, as we found a positive correlation between CVT, acute headache onset $(p=0.001)$ and severe headache $(p=$ 0.004). Therefore, in patients with acute or subacute headache onset of severe intensity CVT should always be considered. However, since headache has no specific features, all cases of unexplained headache in patients at high risk, such as subjects with known states of hypercoagulation or women in pregnancy-puerperium or who take OCs, should raise the clinical suspicion of cerebral venous occlusion.

\subsubsection{Imaging of CVT}

The diagnosis of CVT is based on neuroimaging, particularly on MRI and MRI venography techniques that represent the gold standard and might be used as first-line diagnostic tools in cases of high clinical suspicion. However, an unenhanced CT scan is still the first examination in the emergency room setting. It may show nonspecific lesions, such as hemorrhages, infarcts or edema in isolation or in combination, but which can be normal in up to $25 \%$ of patients.[12] Direct signs of venous thrombosis are seen in only a third of cases. Direct visualization of thrombosis in dural sinus may give a 'dense clot sign' or a 'triangle sign' if the sinus involved in the thrombosis is the superior sagittal sinus. The 'cord sign', although with a low specificity, represents direct visualization of a thrombosed cortical vein that is seen as a linear hyperdensity. The empty delta sign, which may be seen 5 days to 2 months from onset,[27] is the most frequent direct sign of CVT (30\% of patients) and can be seen only on enhanced CT scan. It represents a filling defect (thrombus) in the dural sinus, with peripheral enhancement, possibly secondary to the development of collaterals. An empty delta sign may be mimicked by intrasinus septa or by a split or fenestrated dural sinus, which may manifest as false-positive filling defects.[3,4]

More often, a CT scan only shows the indirect signs of CVT. Diffuse or localized brain edema is seen in $20-50 \%$ of cases. The edema might appear as hypodensity of the brain, decreased ventricular size and cortical sulcal effacement. An infarction not conforming to a major arterial vascular territory, such as the presence of multiple isolated lesions, involvement of a subcortical region with sparing of the cortex and extension over more than one arterial distribution, is highly suspicious for a venous cause. The location of the infarction may give a clue to the venous structure involved. Thrombosis in the sagittal sinus often leads to impaired venous drainage and, therefore, parenchymal change in the parasagittal region. Thrombosis in Labbé's vein should lead to infarction in the temporal lobe. Bilateral or unilateral infarction 
in the thalami, basal ganglia and internal capsule is typically seen in thrombosis of the deep venous system. A hemorrhagic infarction is very frequent, while subarachnoid or subdural hemorrhages are rare manifestations of CVT. Finally, indirect evidence of CVT may be seen as contrast enhancement of the falx and tentorium secondary to venous stasis and hyperemia of the dura mater, which is seen in approximately $20 \%$ of cases.

The key to diagnosis is the imaging of the venous system itself, which may show the occluded vessel or the intravascular thrombus. The current gold standard for CVT diagnosis is the combination of MRI to visualize the thrombosed vessel and magnetic resonance venography to detect the nonvisualization of the same vessel.[28,29] The abnormal signal intensity of thrombus follows the signal characteristics of intracranial hemorrhage and may evolve through the stages of oxyhemoglobin, deoxyhemoglobin, methemoglobin and hemosiderin.[30,31] Usually, the thrombotic material appears isointense in T1 and hypointense in T2 during the first 5 days, subsequently it becomes hyperintense in both the sequences until 1 month. Eventually, the thrombus becomes isointense in both sequences and the persisting vessel occlusion might be documented with angio-MRI techniques. Even with the combination of MRI and magnetic resonance venography, the diagnosis can still be difficult, particularly in isolated cortical vein thrombosis, which requires conventional angiography. Considering the potential risk of this invasive procedure compared with the other techniques, the use of conventional angiography has been restricted, but it is still necessary for cases of isolated cortical thrombosis, for CVT associated with subarachnoid hemorrhage to rule out other causes and for its potential therapeutic approach in selected cases (e.g., failure of anticoagulation therapy).

Some authors have described that on T2-weighted gradient-echo images, exaggerated signal loss is often seen in the first days of CVT, and they concluded that the sequence is useful in isolated cortical venous thrombosis and during the very early days of acute CVT when T1 and T2 lack sensitivity.[32,33] Also, diffusion-weighted imaging may represent a useful tool for CVT diagnosis. In particular, diffusionweighted imaging examination is able to differentiate vasogenic edema, which is more typical of CVT, from cytotoxic edema, which is more typical of arterial ischemia.[34,35] Moreover, early high-intensity diffusion-weighted imaging signal of the thrombosed vein is associated with a low rate of spontaneous recanalization.[36]

Magnetic resonance (MR) venography is important to visualize the venous system and the occluded vessel with the possible presence of collateral flow; MR venography is not useful for cortical vein thrombosis. MR venography may be performed without the use of a contrast agent using the time-offlight (TOF) technique. Unfortunately, this technique is subject to flow-related image artifacts. Contrastenhanced MR venography takes advantage of luminal filling, by contrast, and recently it has been shown to be superior to TOF MR venography. For this reason, the gadolinium-enhanced MR venography might be preferred to the TOF technique, particularly in cases with MRI not exhaustive for CVT diagnosis. Another recent tool that can be used to evaluate CVT is computed tomographic (CT) venography. CT venography allows direct visualization of thrombus as filling defects and is now emerging as a competing technique. It has been shown to be at least comparable to MR venography and, in some situations, to generate more 
diagnostic information.[37] These two techniques probably provide comparable performance and preference will be dictated by the experience and resources of the individual institutions. Finally, for the diagnosis of CVT some authors have reported a possible role of the D-dimer test. D-dimer values are usually elevated in patients with neurological deficits; by contrast, a quarter of patients with headache as the only CVT symptom have a normal D-dimer, underlying a poor diagnostic value of this parameter in this subgroup of patients.[38,39]

\subsubsection{Prognosis of CVT \& Indicators of Outcome}

Before imaging techniques became available, CVT was thought to be a condition associated with a high mortality and disability; $[40,41]$ early reports based on autoptic series even led to the belief that it was invariably fatal. This perception has dramatically changed after the publication of more recent case series that have consistently shown that most patients have a favorable outcome. One of the first reports based on modern diagnostic methods was that of Peters, Ameri and Bousser on a cohort of 77 adult patients who were followed for a mean duration of 77 months.[13] The majority of patients (86\%) had no neurologic sequelae, while the remaining patients survived with neurological deficits. Nine patients out of the 11 who had deficits had focal neurological deficits as the clinical presentation. Recurrence of thrombosis was observed in $20 \%$ of patients and was always within 1 year from the first event. The ISCVT study confirmed these data in a large group and with a prospective enrollment:[22] after a median follow up of 16 months, $57.1 \%$ of patients were asymptomatic and had no signs, $22 \%$ had some neurological sign but no disability (modified Rankin score $=1$ ), $7.5 \%$ had mild impairment, $2.9 \%$ moderate impairment, $2.2 \%$ were severely handicapped and $8.3 \%$ had died. Predictors of a negative outcome found with multivariate analysis were: male sex, coma, mental status disorder, hemorrhage at admission, thrombosis of the deep cerebral venous system, CNS infection and cancer. Recurrence of sinus thrombosis was very low (2.2\%). Wasay et al. reported a higher mortality $(13 \%)$ and dependency $(28 \%$ of patients were bedridden);[12] the best predictors of a negative outcome were coma as the presenting symptom and hemorrhage.

Overall, the available evidence indicates that CVT often has a benign course, as most of the patients recover fully or have only mild sequelae. However, a considerable minority, ranging from 10 to $40 \%$, have a negative outcome despite the therapy. The patients most likely to have a negative clinical evolution are those with reduced awareness, hemorrhagic complications or evidence of thrombosis of the deep venous system. These cases could be considered to be candidates for more aggressive therapies, such as local or systemic thrombolysis or mechanical procedures.

\subsubsection{Therapy}

\section{General Measures}

In patients with venous thrombosis due to external compression or neoplastic infiltration of a dural sinus, treatment of the underlying cause is, of course, necessary. Likewise, a thrombosis of infectious origin, such as those due to spreading of disease from a middle ear infection, requires prompt antibiotic 
treatment and often surgical removal. If increased blood coagulation is due to a hematological or neoplastic pathology, such as leukemia, appropriate treatment should be taken as soon as possible. In patients with reduced consciousness levels, appropriate nursing care and a good fluid homeostasis, as well as management of intercurrent complications, such as infections, is, of course, essential.

\section{Anticoagulants}

Since the pathogenic mechanism responsible for CVT is increased blood coagulation, administration of anticoagulants to affected patients seems to be a promising approach. Anticoagulants may prevent clot growth, which can further impair venous blood drainage from the brain and lead to worsening of the clinical conditions, and could, in theory, shift the balance of the anticoagulation systems, increasing the chance of sinus recanalization. This potential benefit needs to be balanced with the possible increase in

the rate of cerebral and systemic hemorrhage. In a model of chemically induced occlusion of the superior sagittal sinus in rats,[42] low-molecular-weight heparin did not lead to an increase in the rate of recanalization, but was nevertheless associated with a better functional outcome, suggesting that the clinical effect of the drug is mainly due to prevention of occlusion of collateral vessels. In this model, no increase in the rate of bleeding was associated with the therapy.

Heparin and low-molecular-weight heparin have long been employed for the treatment of CVT, and many case descriptions or nonrandomized case series are present in the literature. However, only two relatively small randomized trials of sufficient methodological quality have so far been reported. The first study tested endovenous heparin against placebo (saline solution) and was stopped early, after the recruitment of 20 patients, because a planned interim analysis showed an increased death rate in the placebo group. In total, three patients died and six survived, with a minor deficit in the placebo group, while only two patients had minor deficits in the heparin group and none died.[43] The second trial used fractionated heparin and enrolled 60 patients, showing a nonsignificant trend in favor of nadroparin (poor outcome: 13 vs $21 \%$ of the placebo group).[44] In both studies no symptomatic brain hemorrhage was observed; one case of gastrointestinal bleeding occurred in the second trial. In the first trial, three patients with brain hemorrhage improved with heparin, whereas in the placebo group two patients with previous hemorrhage died and two new symptomatic hemorrhages were observed. Therefore, early concerns of a hemorrhagic risk connected with heparin therapy, based on anecdotal reports, are not confirmed by the randomized trials, demonstrating a high level of safety for the treatment. Thus, concomitant brain hemorrhage consequent to CVT is not a contraindication for heparin therapy. A second possible beneficial effect of anticoagulation may be prevention of pulmonary embolisms from the jugular veins, but no such events were observed. A third study conducted in India showed similar results, but its validity is questionable as the diagnosis of CVT was made on the basis of a CT scan only.[45]

The two trials have been pooled in a Cochrane meta-analysis,[46] which found a nonsignificant relative risk reduction of 0.46 (95\% $\mathrm{Cl}: 0.16-1.31)$ in death or dependency; the absolute risk reduction was $13 \%$ (95\% Cl: -3-30). The relative risk of death was 0.33 (95\% Cl: 0.08-1.21). Although the two trials employed different drugs (unfractionated or fractionated heparin), the meta-analysis was considered possible 
because of consistent demonstration of the equivalence of the two drugs in other settings. Therefore, anticoagulation should be started in all patients with established CVT, either with unfractionated heparin or low-molecular-weight heparinoids, and then continued with oral anticoagulants. The decision of when to stop therapy is often a difficult one, as most recurrent events take place in the first year,[22] thus continuing the treatments beyond this limit does not seem justified. Although the optimal duration of anticoagulation is unknown, the common clinical practice is to continue treatment for at least 3 months in cases of CVT due to intercurrent disease or condition, 6-12 months in idiopathic cases or in cases of mild hereditary thrombophilia, and indefinitely in those with severe thrombophilia.[47]

\section{Thrombolysis}

Some patients continue to worsen and have a negative outcome despite anticoagulation. In this setting, systemic or local thrombolysis could be considered, with the aim of opening the occluded vessel and reducing cerebral hypertension. Indeed, some authors reported a dramatic improvement after thrombolytic treatment, $[48,49,50,51,52]$ and its use as an alternative to anticoagulants in selected patients is increasing. In particular, local (intra-arterial) thrombolysis could be better suited than systemic treatment, as venous clots are larger than arterial ones and are more easily accessible for mechanical revascularization and for injection of the drug directly into the thrombus. In two open uncontrolled trials, one in Korea and one in the USA,[49,52] a total of 21 patients were treated with local thrombolysis, with good results. In total, 15 patients had a complete recanalization of the occluded vessel and 14 recovered completely. However, four patients had major extracerebral bleeding and two who had pretreatment intracerebral hemorrhage worsened. Evidence of brain hemorrhage might represent a contraindication to intra-arterial thrombolysis, although this concept would need to be confirmed by further data from clinical studies.

The patients most likely to benefit from thrombolysis are probably those who present with a coma and those with documented occlusion of the deep venous system, as both of these features, which frequently coexist, are associated with a worse prognosis despite anticoagulation. In addition, patients with occlusion of multiple sinuses have an unfavorable outcome and might be good candidates for a more aggressive treatment. In these patients, the main therapeutic goal is not to prevent a further extension of the thrombotic process, but to re-establish venous outflow in a critical district, thus modifying a condition that is already threatening the patient's survival. In fact, in a review on 38 comatose patients treated with thrombolysis, the observed mortality was $13 \%$ (six cases);[53] as a comparison, the death rate of patients in coma in the ISCVT was $38 \%$.

Despite these preliminary results, at present, no clinical trial to test the safety and effectiveness of this procedure has been reported.[54] The conduction of a randomized controlled trial comparing anticoagulation with thrombolysis is, therefore, needed urgently and may provide significant information that could alter the clinical management of CVT. This will probably represent one of the most likely evolutions in this field (see 'Five-year view' section).

\section{Anti-epileptics}

Page $14 / 42$ 
Cerebral venous thrombosis is associated with a much higher risk of epilepsy than arterial stroke. In the ISCVT, nearly $40 \%$ of patients had a seizure as the presenting symptom of the disease. Furthermore, the same study showed that $6.9 \%$ of the patients had seizure in the first 2 weeks after the diagnosis (these were called 'early seizures').[55] The latter are particularly relevant from a therapeutic point of view as they may represent a serious complication that may be prevented by the administration of anti-epileptics. In the patients of the ISCVT, early seizures were present more often in patients with presenting seizures, motor deficit, superior sagittal sinus or cortical vein thrombosis and the presence of any cerebral lesion. [55] A logistic regression analysis demonstrated that the risk of early seizures was significantly increased in the patients with supratentorial lesions at CT scan or MRI (OR $=3.09 ; 95 \% \mathrm{Cl}: 1.56-9.62)$; patients with presenting seizures had a higher risk without statistical significance $(\mathrm{OR}=1.74 ; 95 \% \mathrm{Cl}$ : 0.9-3.37). Both of these indicators have a biological plausibility, since the presence of a supratentorial ischemic or hemorrhagic lesion is a trigger of epileptic activity and since a seizure at presentation reflects an underlying condition that may facilitate further epileptic events. These prognostic data were confirmed in another study on 194 patients: motor deficit (OR = 5.8; 95\% Cl: 2.98-11.42; $p<0.001)$, intracranial hemorrhage $(\mathrm{OR}=2.8 ; 95 \% \mathrm{Cl}: 1.46-5.56 ; \mathrm{p}=0.002)$ and cortical vein thrombosis $(\mathrm{OR}=2.9 ; 95 \% \mathrm{Cl}: 1.43-$ $5.96 ; p=0.003)$.

The identification of patients at increased epileptic risk may be useful to select those most likely to benefit from antiepileptic therapy. By combining the two indicators, Ferro et al. divided a pooled population from the ISCVT and other smaller studies into four groups: those with neither presenting seizures nor supratentorial lesions, those with either the first or the second feature and those with both. [55] The patients in the first group were largely constituted of patients with isolated intracranial hypertension who presented with headache and no other clinical symptom; these patients had a low natural risk of early seizures $(2.5 \%)$ and benefited little from antiepileptics. The patients with either presenting seizure or supratentorial lesions had a higher rate ( 7.1 and $8.2 \%$, respectively); although antiepileptic treatment in these groups did not reach statistical significance for effectiveness, a clear trend toward a reduction of the crises can be appreciated. Patients with both indicators have a consistent risk of recurrence of seizures and show a clear benefit from therapy ( $51 \%$ without therapy vs $0.7 \%$ with therapy; OR $=0.006 \% ; 95 \% \mathrm{Cl}: 0.001-0.05)$. These data confirm earlier reports on smaller cohorts, in which only patients who had both presenting seizures and brain lesions had recurrence of seizures.[13]

The data presented should be considered with caution as they are derived from non randomized and non blinded studies and, thus, suffer from several methodological limitations, such as a possible unbalancing in clinical severity between patients treated or not treated with antiepileptics. However, since no evidencebased guidelines on this topic are currently available, these results are indeed valuable and have clinical implications. Patients with no brain lesions and who never had seizures should probably not be given antiepileptics, while those with both factors certainly benefit from treatment and are at risk of a worse outcome if not treated. Some uncertainty still exists regarding the indication of patients with a brain lesion but no presenting seizures or who have a first seizure but no parenchymal damage. Although conclusive evidence to treat these patients is currently lacking, the data available seem to indicate a trend towards reduction of crises. We believe, therefore, that the current clinical tendency to administer 
antiepileptics to patients in these two groups is justified and should be continued until more evidence is available. The decision of which antiepileptic to use is not supported by randomized trials; however, drugs with a good activity in focal epilepsy and with low or no interaction with oral anticoagulants should be preferred.

\section{Treatment of Intracranial Hypertension}

Some degree of brain edema is observed in up to $50 \%$ of patients with CVT and is responsible for some of the most frequent symptoms, such as headache and loss of vision. Anticoagulants are often sufficient to reduce brain swelling by increasing the venous outflow; however, further treatment may be needed in patients with visual-field reduction and in those with impaired consciousness.

In the first case, lumbar puncture to reduce cerebrospinal fluid pressure before anticoagulant treatment is established can be useful, but if visual impairment progresses, surgical procedures, such as optic nerve fenestration or ventriculoperitoneal shunting, must be considered. In the second instance, general measures to reduce intracranial hypertension should be taken: the patient's head should be raised by $30^{\circ}$ and intravenous osmotic diuretic should be initiated. If symptoms progress, hyperventilation with a target partial pressure of $\mathrm{CO} 2$ must be established. Treatment with steroids has long been considered an option as it could reduce vasogenic edema; on the other hand, steroids have thrombotic properties and may, therefore, be harmful in CVT. This uncertainty is reflected in current clinical management; in the centers participating in the ISCVT a high variation in the use of steroids was observed (3.3-72\%). The effectiveness of steroids was tested in a case-control retrospective analysis on 300 cases from the ISCVT, [56] showing no benefit from treatment $(\mathrm{OR}=1.7 ; 95 \% \mathrm{Cl}: 0.9-3.3 ; \mathrm{p}=0.119)$. When patients were divided into those with or without lesions at CT-MRI scans, lack of effect was confirmed in the first group (brain lesion: $\mathrm{OR}=1.2 ; \mathrm{Cl}: 0.6-2.7 ; \mathrm{p}=0.675$ ), while a trend towards a detrimental effect of steroid was demonstrated in the second group (no brain lesion: $\mathrm{OR}=4.8 ; 95 \% \mathrm{Cl}: 1.2-19.8 ; \mathrm{p}=0.078$ ). The authors conclude that there is no evidence to recommend steroid use in CVT patients with brain lesions and that they should be avoided in patients without lesions (level III recommendation).

In patients with large hemorrhagic infarctions and transtentorial herniation, decompressive craniotomy is necessary to save the patient's life; some authors reported survival with only minor sequel even in such severe cases.[57] The hemorrhage itself should not be removed as the neuronal damage is limited and may be more easily reversible than in arterial infarction.[47]

CSVT is a multifactorial condition with gender-related specific causes, with a wide clinical presentation, furthermore, the leading causes differ between developed and developing countries, i.e., congenital thrombophilia vs puerperium or $\mathrm{OC}$ use respectively.

CSVT is a condition characterized by a highly variable clinical spectrum, difficult diagnosis, variable etiologies and prognosis that requires fine medical skills and a high suspicious index. Patients who present with CSVT should undergo CVT and to the proper inquiry of the generating cause. It is imperative an intentional search for co-existing causes, as well as the management of post-puncture headaches. 
Correcting the cause, generally the complications can be prevented. Mortality trends have diminished, and with the new technologies, surely it will continue. Treatment strategies are aimed at treating the underlying pathology, controlling $\mathrm{ICH}$, and management of seizures or focal deficits caused by cerebral edema or infarction.

Fifty years ago, CSVT was a mortal condition, but with the introduction of neuroimaging, the mortality rates have become minimal; however, it needs further impetus because great blanks still persist, especially regarding clarification of its management.

\section{Materials And Methods}

\subsection{Study design:}

This is a descriptive prospective hospital-based study.

\subsection{Study population and time:}

The study population included patients with CVST who were admitted in Neurology centers in Khartoum State, Omdurman Teaching Hospital, National Center for Neurological Sciences, Soba Teaching Hospital, and Bashair Teaching Hospital over the period of eight months from March 2020 to October 2020.

\subsection{Study area:}

This study was conducted at neurological centers in Khartoum State, including Omdurman Teaching Hospital, National Center for Neurological Sciences, Soba Teaching Hospital, and Bashair Teaching Hospital.

\subsubsection{Inclusion criteria:}

All patients who presented to the specified neurological centers, during the study period, and were diagnosed with cerebral venous sinus thrombosis were included in the study.

\subsubsection{Exclusion criteria:}

We excluded all patients younger than 18 years of age and those who did not consent to participate in the study.

\subsection{Sample size:}

Our sampling method was the total coverage of all patients fulfilling the study criteria. The number was 60 patients.

\subsection{Data collection:}


Data was collected using a structured standardized interviewer administered questionnaire, consisting of detailed history (including personal data, symptoms and signs of CVT, past medical history, family history, and social history), in addition to investigation results and treatment.

Clinical examination was done for all patients and included: general examination, central nervous system examination looking for evidence of cerebral venous thrombosis.

The following investigations were done for each patient: CBC, RBG, LFT, RFT, INR, thrombophilia screening, connective tissue disease screening.

Brain MRI and MRV, brain CT and brain CTV were done for some patients.

\subsection{Data analysis:}

Data was entered to the computer from a master sheet using a software program. It was entered and analyzed in the Statistical Package for Social Sciences (SPSS 26).

\subsection{Ethical considerations:}

The proposal was presented to the ethics review committee of the Sudan Medical Specialization Board, Council of MD Neurology for approval of the study.

All patients were adult Sudanese patients (defined as age of 18 years or more). All patients gave their consent to participate in the study. The participants were aware of their rights throughout the study; participation in the study was completely voluntary and confidentially considered.

A written approved consent was taken from the concerned hospitals.

\subsection{Objective}

General objective:

- To describe the etiological associations of CVST among Sudanese patients.

Specific objectives:

- To identify the risk factors of CVST in Sudanese patients.

- To correlate between clinical features and the findings of the brain imaging of CVT patients.

- To assess the outcome of management of CVST.

\section{Results}

Sixty patients with cerebral venous thrombosis were included in this study, 50 of them (83.3\%) were females and 10(16\%) were males. Nine patients (15\%) aged 18 to 25 years, $45(75 \%)$ aged 26 to 50 and 6 $(10 \%)$ aged more than 50 . Thirty seven patients (61.7\%) resided in Khartoum State and $23(38.3 \%)$ in 
other states. Two patients $(0.03 \%)$ were single, $49(81.7 \%)$ were married, $3(5 \%)$ were widowed and 6 $(10 \%)$ were divorced. Regarding occupation, 3 patients (5\%) were office employees, 5 (8.3\%) were laborers, 51 (85\%) were house wives and $1(1.7 \%)$ was retired.

Regarding clinical presentation, headache was found in all patients, seizures in 46 (76\%), disturbed consciousness in $12(20 \%)$, abnormal behavior in $9(15 \%)$, visual disturbances in 49 (81.7\%), diplopia in 3 (5\%), fever in $7(11.7 \%)$, neck stiffness in $2(3.3 \%)$, weakness in $12(20 \%)$. Regarding the clinical examination signs abnormal speech was found in 8 patients (13.3\%), memory disturbances in $8(13.3 \%)$, evidence of CN VI lesion in $3(5 \%)$, papilledema in 49 (81.7\%), Hemiparesis in $46(76.7 \%)$, paraparesis in 6 (10\%), quadriparesis in $2(11.7 \%)$ and monoparesis in 1 (1.7\%). Abnormal sensory signs were only found in one patient.

Post-partum period was a risk factor in 23 patients (38.3\%), pregnancy in 15 (25\%), OCP in 11 (18.3), dehydration in $5(8.3 \%)$, nephrotic syndrome in $2(3.3 \%)$ and IBD in $1(1.7 \%)$. Regarding past medical history: Hypertension was detected in $1(1.7 \%)$ patient, malignancy in $3(5 \%)$, rheumatologic and connective tissue disease in $1(1.7 \%)$ and skin disease in $1(1.7 \%)$.

Abnormalities found in investigation results were as follows: CBC in $3(5 \%)$ patients, ESR in 2 (3.3\%), RBS in $2(3.3 \%), \mathrm{PT}$, RFT and LFT were normal in all patients. ANA was abnormal in 1 (1.7\%) patient, AntiDNA in $1(1.7 \%)$, Lupus antibody in 1 (1.7\%), Anticardiolipine antibody in 1 (1.7\%), Protein $C$ in $3(5 \%)$, Protein $S$ in $3(5 \%)$. Antithrombin III, B20 210MAB gene screening, and Factor $\mathrm{V}$ leiden screening were requested for seven patients but was not done by the others. MRI/MRV was abnormal in all the patients. Extensive sinus involvement was found in 6 patients, the superior sagittal sinus in 35 patients and the transverse sinus in 19 patients.

Low molecular weight heparin was administered to 2 patients (3.3\%),warfarin to 26 (43.3\%) and rivaroxaban to $26(43.3 \%)$. Intracranial pressure management was done to all patients. Acetazolamide was administered to 49 patients, Intervention therapy (LP shunt) to 2 and repeated lumbar puncture to 9. Forty five patients (75\%) fully recovered after treatment, but 11 (18.3\%) partially recovered and 4 (6.7\%) died.

\section{Discussion}

Our study included 60 patients with cerebral venous sinus thrombosis assessed for the etiological associations. The study showed that most of the patients are young females. The mean age was found to be 35 years.

The clinical features showed that all of our patients suffered from headache, and the majority of them had seizures, visual disturbances, and focal neurological deficits, and $46 \%$ revealed papilledema. This is compatible with the results of a large prospective observational study and some are in contrast to what was mentioned in literature. Only a few patients had symptoms of fever and neck pain which is different 
to what was mentioned in the literature. Our study revealed that some patients had diplopia due to sixth cranial nerve involvement. This is similar to what was mentioned in the literature.

Some of the patients with CVST had nephrotic syndrome, Ca breast and connective tissue disease (SLE) this is compatible with the result of a large prospective observational study. The study revealed that postpartum, pregnancy and usage of OCP were found to be more associated risk factors in our study; this is compatible with what was mentioned in the literature.

The study revealed that some patients had low levels of protein $C$ and $S$, this is similar to what was mentioned in the literature. It did appear that all patients with CVST had abnormal imaging including Brain MRI, MRV and some of them had abnormal Brain CT, CTV, which is compatible with what was mentioned in the literature. The study showed that superior sagittal sinus thrombosis and transverse sinus thrombosis were more common types of CVST, this is similar to the result of a large prospective observational study.

Intracranial pressure reduction therapy was administered to all of our patients, with the majority receiving acetazolamide, and only a few receiving repeated LP, and LP shunt, which is compatible with the literature. All of our patients received anticoagulation, including $\mathrm{LMWH}$, and oral anticoagulation (rivaroxaban or warfarin), which is similar to other populations. Our study showed that most treated patients with CVST had good outcomes. This is compatible with what was mentioned in the literature.

\subsection{Conclusion}

This study revealed that post-partum, pregnancy and oral contraceptive pills were the most common etiological associations of cerebral venous sinus thrombosis compared with other populations.

Females were more common than males in the study.

Headache and papilledema had the highest occurrence in our patients

Superior sagittal sinus thrombosis and transverse sinus thrombosis were the most common types of cerebral venous sinus thrombosis in our study.

Most of our patients in this study had good outcomes.

\subsection{Recommendations}

Cerebral venous sinus thrombosis should be considered in the differential diagnosis of any patients who have risk factors for Cerebral venous sinus thrombosis and share symptoms and signs of other neurological diseases at presentation.

Because cerebral venous sinus thrombosis is a treatable condition and has good outcomes, the early detection of patients and performing suitable work up is essential. 
We should advice and encourage the women with the workers in these sectors (Obstetricians and Gynecologists, midwives and general practitioner) regarding the early mobility after the delivery and knowing the side effects of oral contraceptive uses particularly those at high risk with avoidance of tight circumcision as much as possible to increase postpartum mobility.

We should consider the possibility of cerebral venous sinus thrombosis in any abnormal finding in the image that is not compatible with arterial territories.

We must do full workup for thrombophilia screening and connective tissue diseases, because the disease has the tendency to recur, and the patients may need lifelong treatment.

Because the visual insult is common in cerebral venous sinus thrombosis with a nasty sequel, ophthalmological and neurosurgical consultation has paramount importance. Further studies in this field are mandatory.

\section{Declarations}

\section{Consent for publication}

Not applicable.

\section{Availability of data and materials}

The materials datasets used and/or analyzed during this study are available from the corresponding author on reasonable request.

\section{Competing interests}

The authors declare that they have no competing interests.

\section{Funding}

This research did not receive any specific grant from funding agencies in the public, commercial, or notfor-profit sectors.

\section{Authors' contributions}

All authors participated in planning the study, data collection, results and discussion sections.

\section{Acknowledgements}

Not applicable.

\section{References}


1. Bousser MG, Ferro JM. Cerebral venous thrombosis: An update. Lancet Neurol 2007;6:162-70.

2. Bousser MG, Crassard I. Cerebral venous thrombosis, pregnancy and oral contraceptives. Thromb Res 2012;130: S19-22.

3. Ferro JM, Canhão P, Stam J, Bousser MG, Barinagarrementeria F; ISCVT Investigators. et al. Prognosis of cerebral vein and dural sinus thrombosis: Results of the international study on cerebral vein and dural sinus thrombosis (ISCVT). Stroke 2004;35:664-70.

4. Canh ao P, Ferro JM, Lindgren AG, Bousser MG, Stam J, Barinagarrementeria F. Causes and predictors of death in cerebral venous thrombosis. Stroke 2005; 36: 1720-5.

5. Lauw, M. N., Barco, S., Coutinho, J. M. \& Middeldorp, S. Cerebral venous thrombosis and thrombophilia: a systematic review and meta-analysis. Semin. Thromb. Hemost. 2013;39, 913-927.

6. Dentali F, Crowther M, Ageno W. Thrombophilic abnormalities, oral contraceptives, and risk of cerebral vein thrombosis: a meta-analysis. Blood. 2006; 107(7): 2766-73.

7. Stam J: Thrombosis of the cerebral veins and sinuses. N Engl J Med. 2005; 352:1791-1798.

8. Coutinho, J. M. Cerebral venous thrombosis. J. Thromb. Haemost. 2015;13 (Suppl. 1), S238-S244.

9. Ferro JM, Bousser MG, Canhão P, et al; European Stroke Orga nnization. European Stroke Organization guideline for the diagnosis and treatment of cerebral venous thrombosis - endorsed by the European Academy of Neurology. Eur J Neurol 2017;24(10):1203-1213.

10. Saposnik G, Barinagarrementeria F, Brown RD Jr, Bushnell CD, Cucchiara B, Cushman M, et al. Diagnosis and management of cerebral venous thrombosis: a statement for healthcare professionals from the American Heart Association/American Stroke Association. Stroke. 2011; 42(4): 1158-92.

11. Miranda B, Ferro JM, Canh ao P, Stam J, Bousser MG, Barinagarrementeria F, Scoditti U. Venous thromboembolic events after cerebral vein thrombosis. Stroke 2010; 41: 1901-6.

12. Bousser MG, Ferro MJ. Cerebral venous thrombosis: an update. Lancet Neurol. 6, 162-170 (2007).

13. Schaller B, Graf R. Cerebral venous infarction: the pathophysiological concept. Cerebrovasc. Dis. 18, 179-188 (2004).

14. Provenzale JM, Joseph GJ, Barboriak DP. Dural sinus thrombosis: findings on CT and MR imaging and diagnostic pitfalls. AJR Am. J. Roentgenol. 170, 777-783 (1998).

15. Poon CS, Chang J, Swarnkar A, Johnson MH, Wasenko J. Radiologic diagnosis of cerebral venous thrombosis: pictorial review. AJR Am. J. Roentgenol. 189(6 Suppl.),S64-S75 (2007).

16. Corvol JC, Oppenheim C, Manai R et al. Diffusion-weighted magnetic resonance imaging in a case of cerebral venous thrombosis. Stroke 29, 2649-2652 (1998).

17. Yoshikawa $\mathrm{T}$, Abe $\mathrm{O}$, Tsuchiya $\mathrm{K}$ et al. Diffusion-weighted magnetic resonance imaging of dural sinus thrombosis. Neuroradiology 44, 481-488 (2002).

18. Masuhr F, Busch $\mathrm{M}$, Amberger $\mathrm{N}$ et al. Risk and predictors of early epileptic seizures in acute cerebral venous and sinus thrombosis. Eur. J. Neurol. 8, 852-856 (2006). 
19. Cerebral Venous Sinus Thrombosis: Clinical and Epidemiological Studies. de Bruijn SFTM (Ed.). Thesis Publishers, Amsterdam, The Netherlands (1998).

20. Singh S, Kumar S, Joseph M, Gnanamuthu C, Alexander M. Cerebral venous sinus thrombosis presenting as subdural haematoma. Australas. Radiol. 49, 101-103 (2005).

21. Shad A, Rourke TJ, Hamidian Jahromi A, Green AL. Straight sinus stenosis as a proposed cause of perimesencephalic non-aneurysmal haemorrhage. J. Clin. Neurosci. 15, 839-841 (2008).

22. Ferro JM, Canhao P, Stam J, Bousser MG, Barinagarrementeria F. Prognosis of cerebral vein and dural sinus thrombosis: results of the International Study on Cerebral Vein and Dural Sinus Thrombosis (ISCVT). Stroke 35, 664-670 (2004).

23. Wasay $M$, Bakshi R, Bobustuc $G$ et al. Cerebral venous thrombosis: analysis of a multicenter cohort from the United States. J. Stroke Cerebrovasc. Dis. 17, 49-54 (2008).

24. Preter M, Tzourio C, Ameri A, Bousser MG. Long-term prognosis in cerebral venous thrombosis follow-up of 77 patients. Stroke 27, 243-246 (1996).

25. Agostoni E. Headache in cerebral venous thrombosis. Neurol. Sci. 25, S206-S210 (2004).

26. Martinelli I, Sacchi E, Landi G, Taioli E, Duca F, Mannucci PM. High risk of cerebral-vein thrombosis in carriers of a prothrombin-gene mutation and in users of oral contraceptives. N. Engl. J. Med. 338, 1793-1797 (1998).

27. de Bruijn SF, Stam J, Vandenbroucke JP. Increased risk of cerebral venous sinus thrombosis with third-generation oral contraceptives. Lancet 351, 1404 (1998).

28. Lanska DJ, Kryscio RJ. Risk factors for peripartum and postpartum stroke and intracranial venous thrombosis. Stroke 31, 1274-1282 (2000).

29. Gadelha T, Andrè C, Jucà AA, Nucci M. Prothrombin 20210A and oral contraceptive use as risk factors for cerebral venous thrombosis. Cerebrovasc. Dis. 19, 49-52 (2005).

30. Ciccone A, Gatti A, Melis M et al. Cigarette smoking and risk of cerebral sinus thrombosis in oral contraceptive users: a case control study. Neurol. Sci. 26, 319-323 (2005).

31. Stolz E, Valdueza JM, Grebe M et al. Anemia as a risk factor for cerebral venous thrombosis? An old hypothesis revisited. Results of a prospective study. J. Neurol. 254, 729-734 (2007).

32. Einhaupl KM, Villringer A, Harberl RL et al. Clinical spectrum of sinus venous thrombosis. In: Cerebral Sinus Thrombosis: Experimental and Clinical Aspects. Einhaulp KM, Kempski O, Baethmann A (Eds). Plenum Press, NY, USA 149-156 (1990).

33. Biousse V, Ameri A, Bousser MG. Isolated intracranial hypertension as the only sign of cerebral venous thrombosis. Neurology 53, 1537-1542 (1999).

34. Masuhr F, Mehraein S, Einhaupl K Cerebral venous and sinus thrombosis. J. Neurol. 251, 11-23 (2004).

35. Newman DS, Levine SR, Curtis VL, Welch KMA. Migraine like visual phenomena associated with cerebral venous thrombosis. Headache 29, 82-85 (1989). 
36. De Brujin SFTM, Stam J, Kappelle LJ; for CVST Study Group. Thunderclap headache as first symptom of cerebral venous sinus thrombosis. Lancet 348, 1623-1625 (1996).

37. Landtblom AM, Fridriksson S, Boive $J$ et al. Sudden onset headache: a prospective study of feature, incidence and causes. Cephalalgia 22, 354-360 (2002).

38. Emil J, Lee Y. The empty delta sign. Radiology(224), 788-789 (2002).

39. Dormont D, Anxionnat R, Evrard S, Louaille C, Chiras J, Marsault C. MRI in cerebral venous thrombosis. J. Neuroradiol. 21, 81-99 (1994).

40. Isensee C, Reul J, Thron A. Magnetic resonance imaging of thrombosed dural sinuses. Stroke 25, 2934 (1994).

41. Bousser MG. Cerebral venous thrombosis: diagnosis and management. J. Neurol. 247, 252-258 (2000).

42. Lee S-K, Brugge KG. Cerebral venous thrombosis in adults: the role of imaging evaluation and management. Neuroimaging Clin. N. Am. 13, 139-152 (2003).

43. Zimmerman RD, Ernst RJ. Neuroimaging of cerebral venous thrombosis. Neuroimaging Clin. $N$. Am. 2, 463-485 (1992).

44. Selim M, Fink J, Linfante I, Kumar S, Schlaug G, Caplan LR. Diagnosis of cerebral venous thrombosis with echo-planar T2*SW-weighted magnetic resonance imaging. Arch. Neurol. 59, 1021-1026 (2007).

45. Cakmak S, Hermier M, Montavont A, et al. T2*SW-weighted MRI in cortical venous thrombosis. Neurology 63, 1698 (2004).

46. Lövblad KO, Bassetti C, Schneider J et al. Diffusion-weighted MR in cerebral venous thrombosis. Cerebrovasc. Dis. 11, 169-176 (2001).

47. Idbaih A, Boukobza M, Crassard I, Porcher R, Bousser MG, Chabriat H. MRI of clot in cerebral venous thrombosis high diagnostic value of susceptibility-weighted images. Stroke 37, 991-995 (2006).

48. Ozsvath RR, Casey SO, Lustrin ES, Alberico RA, Hassankhani A, Patel M. Cerebral venography: comparison of CT and MR projection venography. AJR Am. J. Roentgenol. 169, 1699-1707 (1997).

49. Lalive PH, de Moerloose P, Lövblad K, Sarasin FP, Mermillod Sztajzel R. Is measurement of D-dimer useful in the diagnosis cerebral venous thrombosis? Neurology 61, 1057-1060 (2003).

50. Crassard I, Soria C, Tzourio C, et al. A negative D-dimer assaydoes not rule out cerebral venous thrombosis: a series of 73 patients. Stroke 36, 1716-1719 (2005).

51. Ribes MF. Des recherches faites sur la phlébite. Revue Médicale Française et Etrangère et Journal de Clinique de l'Hôtel-Dieu et de la Charité de Paris 3, 5-41 (1825).

52. Barnett HJ, Hyland HH. Non-infective intracranial venous thrombosis. Brain 76, 36-49 (1953).

53. Röttger $C$, Madlener $\mathrm{K}$, Heil $\mathrm{M}$ et al. Is heparin treatment the optimal management for cerebral venous thrombosis? Effect of abciximab, recombinant tissue plasminogen activator, and enoxaparin in experimentally induced superior sagittal sinus thrombosis. Stroke 36, 841-846 (2005).

54. Einhaupl KM, Villringer A, Meister W et al. Heparin treatment in sinus venous thrombosis. Lancet 338, 597-600 (1991). 
55. de Bruijn SFTM, Stam J; for the Cerebral Venous Sinus Thrombosis Study Group. Randomised, placebo-controlled trial of anticoagulant treatment with low-molecular weight heparin for cerebral sinus thrombosis. Stroke 30, 484-488 (1999).

56. Nagaraja D, Rao BSS, Taly AB, Subhash MN. Randomized controlled trial of heparin in puerperal cerebral venous/sinus thrombosis. Nimhans J. 13, 111-115 (1995).

57. Stam J, De Bruijn SF, DeVeber G. Anticoagulation for cerebral sinus thrombosis. Cochrane Database Syst. Rev. 4,CD002005 (2002).

58. Einhäupl K, Bousser MG, de Bruijn SFTM et al. EFNS Guideline on the treatment of cerebral venous and sinus thrombosis. Eur J. Neurol. 13, 553-559 (2006).

59. Chow K, Gobin YP, Saver J, Kidwell C, Dong P, Viñuela F. Endovascular treatment of dural sinus thrombosis with rheolytic thrombectomy and intra-arterial thrombolysis. Stroke 3, 1420-1425 (2000).

60. Frey JL, Muro GJ, McDougall CG, Dean BL, Jahnke HK. Cerebral venous thrombosis: combined intrathrombus rtPA and intravenous heparin. Stroke 30, 489-494 (1999).

61. Smith AG, Cornblath WT, Deveikis JP. Local thrombolytic therapy in deep cerebral venous thrombosis. Neurology 48, 1613-1619 (1997).

62. Renowden SA, Oxbury J, Molyneux AJ. Case report: venous sinus thrombosis: the use of thrombolysis. Clin. Radiol. 52, 396-399 (1997).

63. Kim SY, Suh JH. Direct endovascular thrombolytic therapy for dural sinus thrombosis: infusion of alteplase. Am. J. Neuroradiol. 18, 639-645 (1997).

64. Canhão P, Falcão F, Ferro JM. Thrombolytics for cerebral sinus thrombosis. A systematic review. Cerebrovasc. Dis. 15, 159-166 (2003).

65. Ciccone A, Canhão P, Falcão F, Ferro JM, Sterzi R. Thrombolysis for cerebral vein and dural sinus thrombosis. Cochrane Database Syst. Rev. 1, CD003693 (2004).

66. Ferro JM, Canhão P, Bousser MG, Stam J, Barinagarrementeria F; ISCVT Investigators. Early seizures in cerebral vein and dural sinus thrombosis: risk factors and role of antiepileptics. Stroke 39, 11521158 (2008).

67. Canhão P, Cortesão A, Cabral M et al.; ISCVT Investigators. Are steroids useful to treat cerebral venous thrombosis? Stroke 39, 105-110 (2008).

68. Stefini R, Latronico N, Cornali C, Rasulo F, Bollati A. Emergent decompressive craniectomy in patients withfixed dilated pupils due to cerebral venous and dural sinusthrombosis: report of three cases. Neurosurgery 45, 626-629 (1999).

\section{Tables}

Table 1: demographic characteristics 


\begin{tabular}{|c|c|c|}
\hline Demographic characteristics & frequencies & Percentage \\
\hline \multicolumn{3}{|l|}{ Gender } \\
\hline Male & 10 & 16.7 \\
\hline Female & 50 & 83.3 \\
\hline \multicolumn{3}{|l|}{ Marital status } \\
\hline Single & 2 & $3.3 \%$ \\
\hline Married & 49 & $81.7 \%$ \\
\hline Widow & 3 & $5 \%$ \\
\hline Divorced & 6 & $10 \%$ \\
\hline \multicolumn{3}{|l|}{ Age group } \\
\hline $18-25$ & 9 & $15 \%$ \\
\hline $26-50$ & 45 & $75 \%$ \\
\hline$>50$ & 6 & $10 \%$ \\
\hline \multicolumn{3}{|l|}{ Residence } \\
\hline Khartoum State & 37 & $61.7 \%$ \\
\hline Outside Khartoum & 23 & $38.3 \%$ \\
\hline \multicolumn{3}{|l|}{ occupation } \\
\hline Employee & 3 & $5 \%$ \\
\hline Laborer & 5 & $8.3 \%$ \\
\hline $\mathrm{W} / \mathrm{H}$ & 51 & $85 \%$ \\
\hline Retired & 1 & $1.7 \%$ \\
\hline
\end{tabular}

Table (2) the distribution of the study participants according to the clinical symptoms $(n=60)$ 


\begin{tabular}{|l|l|l|}
\hline & Frequency & Percent \\
\hline Headache & 60 & 100.0 \\
\hline Seizures & 46 & 76.7 \\
\hline Visual disturbances & 49 & 81.7 \\
\hline Abnormal behavior & 9 & 15.0 \\
\hline Weakness & 12 & 20.0 \\
\hline Fever & 7 & 11.7 \\
\hline
\end{tabular}

Table (3) the distribution of the study participants according to clinical signs $(\mathrm{n}=60)$

\begin{tabular}{|l|l|l|}
\hline & Frequency & Percent \\
\hline Disturb LOC & 12 & 20 \\
\hline Memory disturbance & 8 & 13.3 \\
\hline Speech disturbance & 8 & 13.3 \\
\hline Cranial nerve VI involvement & 3 & 5.1 \\
\hline Papilledema & 48 & 80 \\
\hline Neck stiffness & 2 & 3.3 \\
\hline Motor weakness & 12 & 20 \\
\hline Sensory disturbance & 1 & 1.7 \\
\hline
\end{tabular}

Table (4) the distribution of the study participants according to the risk factors ( $\mathrm{n}=60$ )

\begin{tabular}{|l|r|r|}
\hline & Frequency & Percent \\
\hline Pregnancy & 15 & 25.0 \\
OCP & 11 & 18.3 \\
Dehydration & 5 & 8.3 \\
Post partum & 25 & 41.7 \\
NS & 1 & 1.7 \\
malignancy & 1 & 1.7 \\
CTD & 2 & 3.3 \\
Total & 60 & 100 \\
\end{tabular}


Table (5) the distribution of the study participants according to the past medical history $(n=60)$

\begin{tabular}{|l|l|l|}
\hline & Frequency & Percentage \\
\hline HTN & 1 & 1.7 \\
\hline Malignancy & 1 & 1.7 \\
\hline Rheumatological disease or CTD & 2 & 3.4 \\
\hline Nephrotic syndrome & 1 & 1.7 \\
\hline
\end{tabular}

Table (6) the distribution of the study participants according to the type of intracranial pressure reduction therapy received $(\mathrm{n}=60)$

\begin{tabular}{|l|l|l|}
\hline & Frequency & Percent \\
\hline Acetazolamide & 49 & 81.6 \\
\hline Intervention therapy (LP shunt) & 2 & 3.4 \\
\hline Repeated lumbar puncture & 9 & 15 \\
\hline
\end{tabular}

Table (7) the distribution of the study participants according to the outcome $(n=60)$

\begin{tabular}{|l|r|r|}
\hline & Frequency & Percent \\
\hline Full recovery & 45 & 75.0 \\
Partial recovery & 11 & 18.3 \\
Death & 4 & 6.7 \\
Total & 60 & 100.0 \\
\hline
\end{tabular}

Table (8) the distribution of the study participants according to the results of general investigations $(n=60)$ 


\begin{tabular}{|l|l|l|}
\hline & Frequency & Percent \\
\hline CBC & 57 & 95 \\
\hline ESR & 58 & 96.7 \\
\hline PT & 60 & 100 \\
\hline RFT & 60 & 100 \\
\hline LFT & 60 & 100.0 \\
\hline RBS & 58 & 96.7 \\
\hline
\end{tabular}

Table (9) the distribution of the study participants according to the results of connective tissue disease screening $(n=60)$

\begin{tabular}{|l|l|l|}
\hline & Frequency & Percent \\
\hline ANA & 1 & 1.7 \\
\hline AntiDNA & 1 & 1.7 \\
\hline Lupus Antibody & 1 & 1.7 \\
\hline Anticardiolipine & 1 & 1.7 \\
\hline
\end{tabular}

Table (10) the distribution of the study participants according to the results of thrombophilia screening $(n=60)$

\begin{tabular}{|l|l|l|}
\hline & Frequency & Percent \\
\hline Protein C & 5 & 8.3 \\
\hline Protein S & 3 & 5 \\
\hline Antithrombin III & 0 & 0 \\
\hline B20 210MAB & 0 & 0 \\
\hline Factor V leiden & 0 & 0 \\
\hline
\end{tabular}

Table (11) the distribution of the study participants according to the type of imaging study performed $(\mathrm{n}=60)$

\begin{tabular}{|l|l|l|}
\hline & Frequency & Percent \\
\hline MRI/MRV & 7 & 11.6 \\
\hline CT/CTV & 53 & 88.3 \\
\hline
\end{tabular}


Table (12) the distribution of the study participants according to the type of venous sinus thrombosis $(n=60)$

\begin{tabular}{|l|l|l|}
\hline & Frequency & Percent \\
\hline Extensive sinus involvement & 6 & 10 \\
\hline Superior sagital sinus & 35 & 58.3 \\
\hline Transverse sinus & 19 & 31.6 \\
\hline
\end{tabular}

Table (13) the distribution of the study participants according to the results of optical coherence tomography $(\mathrm{n}=60)$

\begin{tabular}{|l|l|l|}
\hline & Frequency & Percent \\
\hline Normal & 44 & 73.3 \\
\hline Abnormal & 16 & 23.6 \\
\hline
\end{tabular}

Table (14) the distribution of the study participants according to the type of medical treatment received $(\mathrm{n}=60)$

\begin{tabular}{|l|l|l|}
\hline & Frequency & Percent \\
\hline UF H & 2 & 3.3 \\
\hline LMWH & 13 & 21.7 \\
\hline Warfarin & 26 & 43.3 \\
\hline Rivaroxaban & 26 & 43.3 \\
\hline ICP management & 60 & 100.0 \\
\hline
\end{tabular}

\section{Figures}

Image not available with this version 
Figure 1

Figure not available in this version.

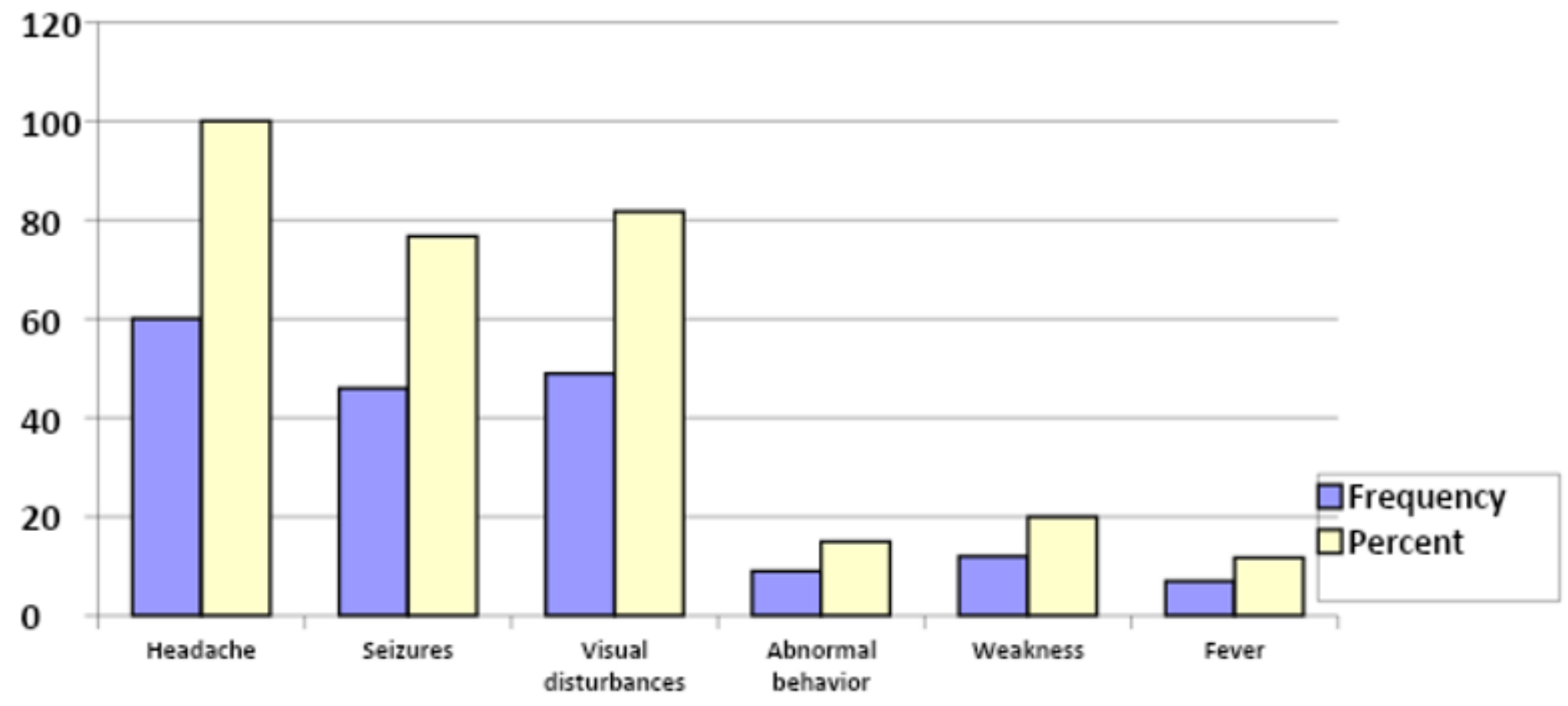

Figure 2

The distribution of the study participants according to the clinical symptoms $(n=60)$

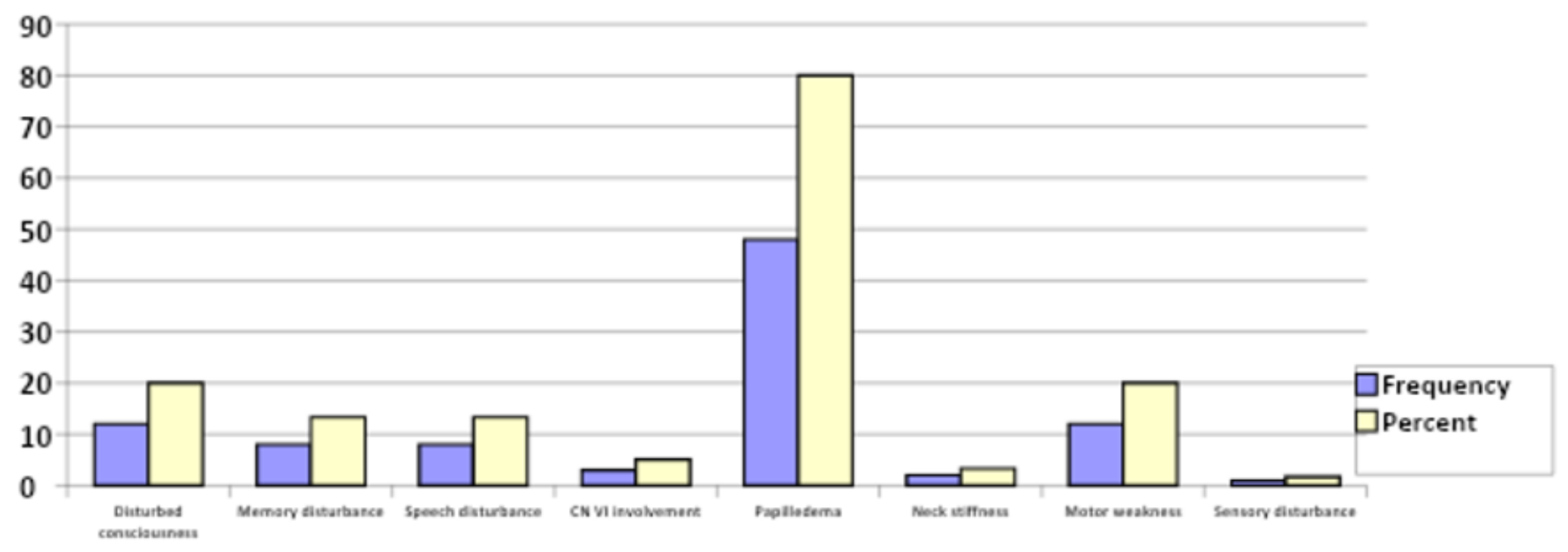

Figure 3

The distribution of the study participants according to clinical signs $(n=60)$ 
Risk factors

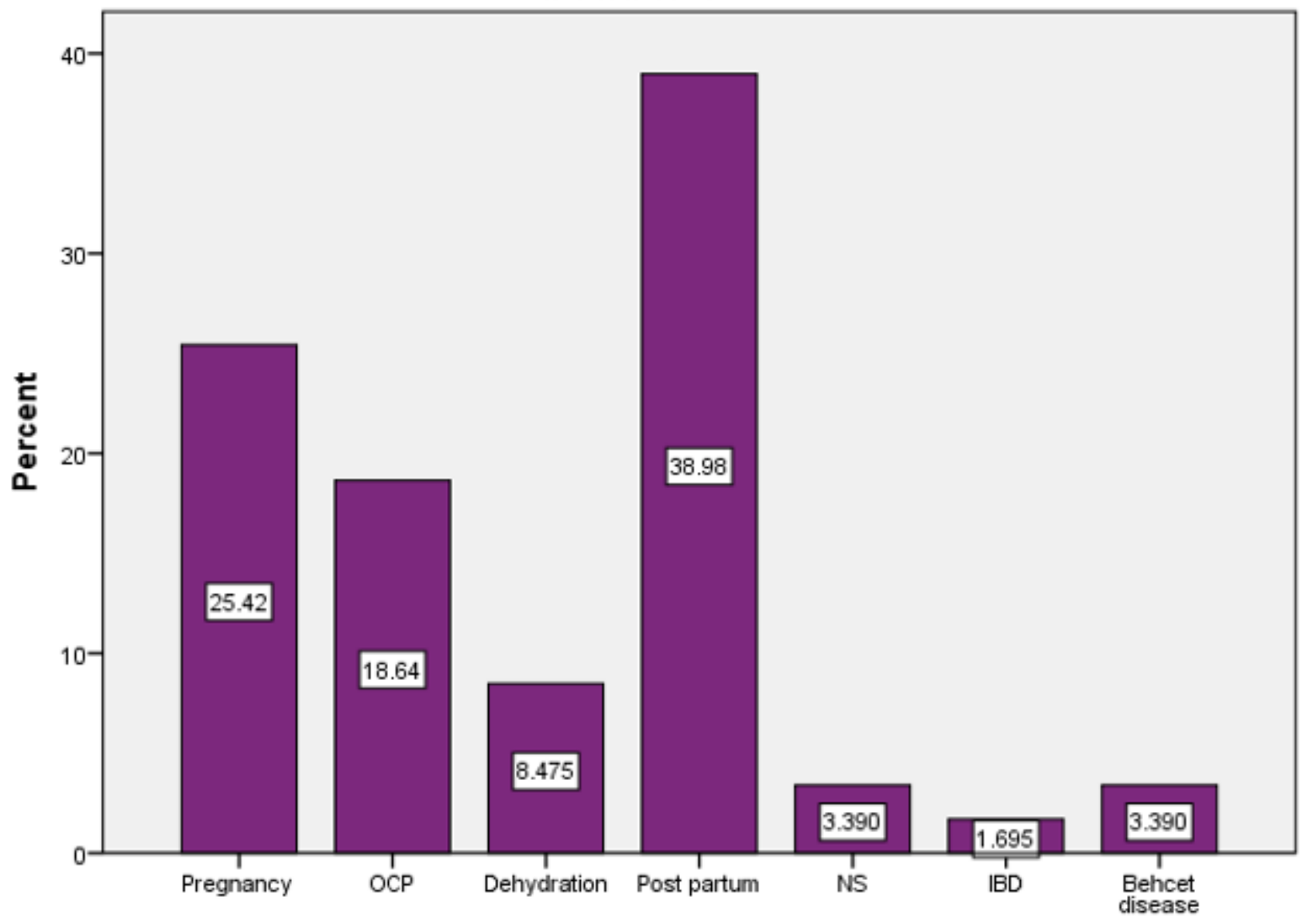

Figure 4

The distribution of the study participants according to the risk factors $(n=60)$

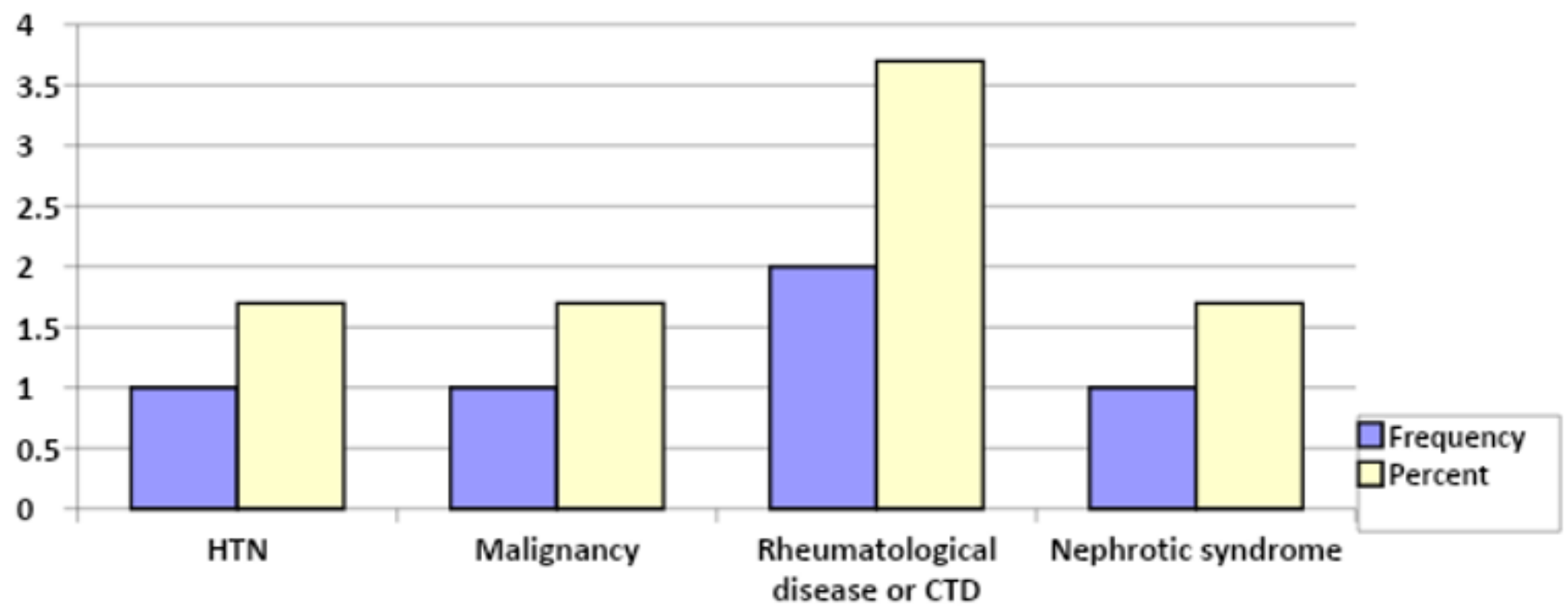

Figure 5

The distribution of the study participants according to the past medical history ( $n=60)$ 
Intracranial pressure reduction therapy

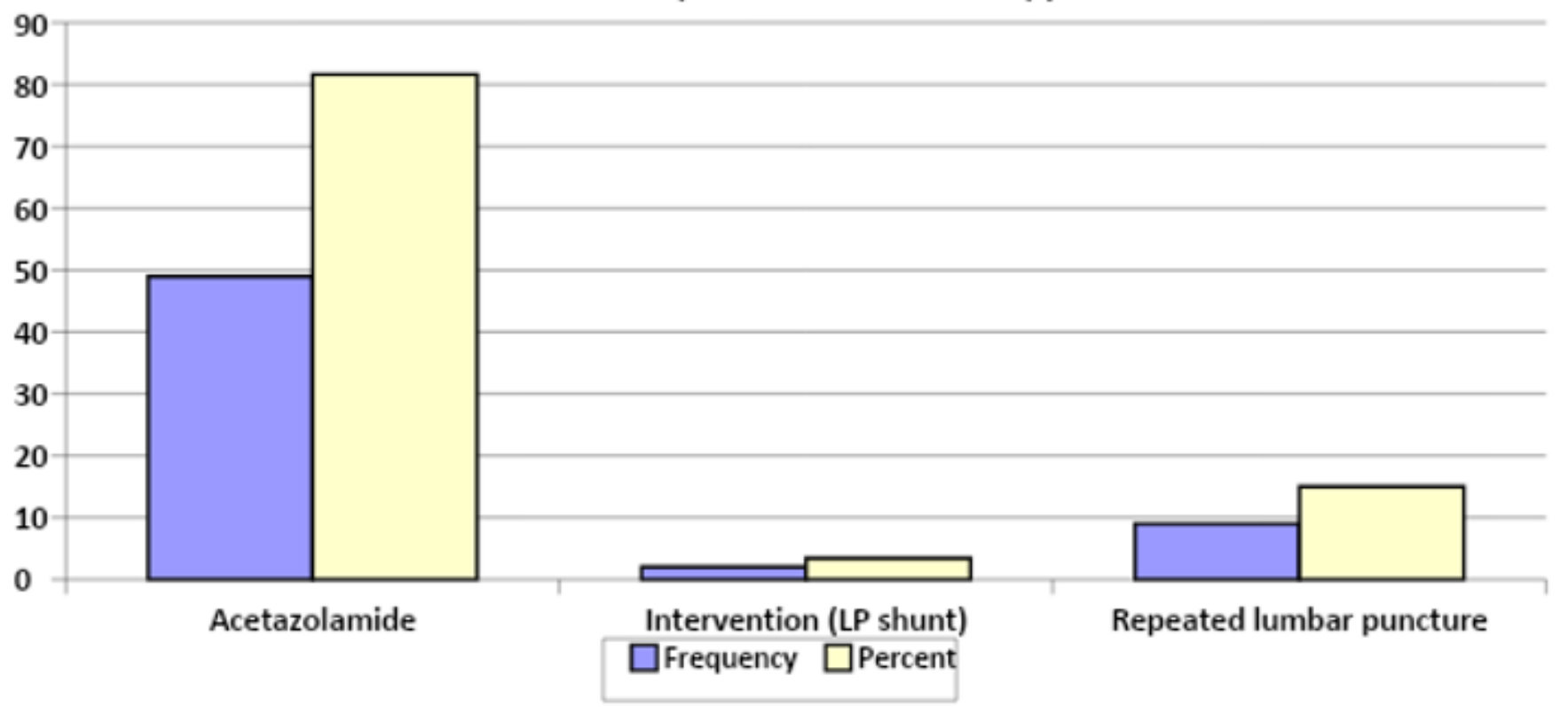

Figure 6

The distribution of the study participants according to the type of intracranial pressure reduction therapy received $(n=60)$

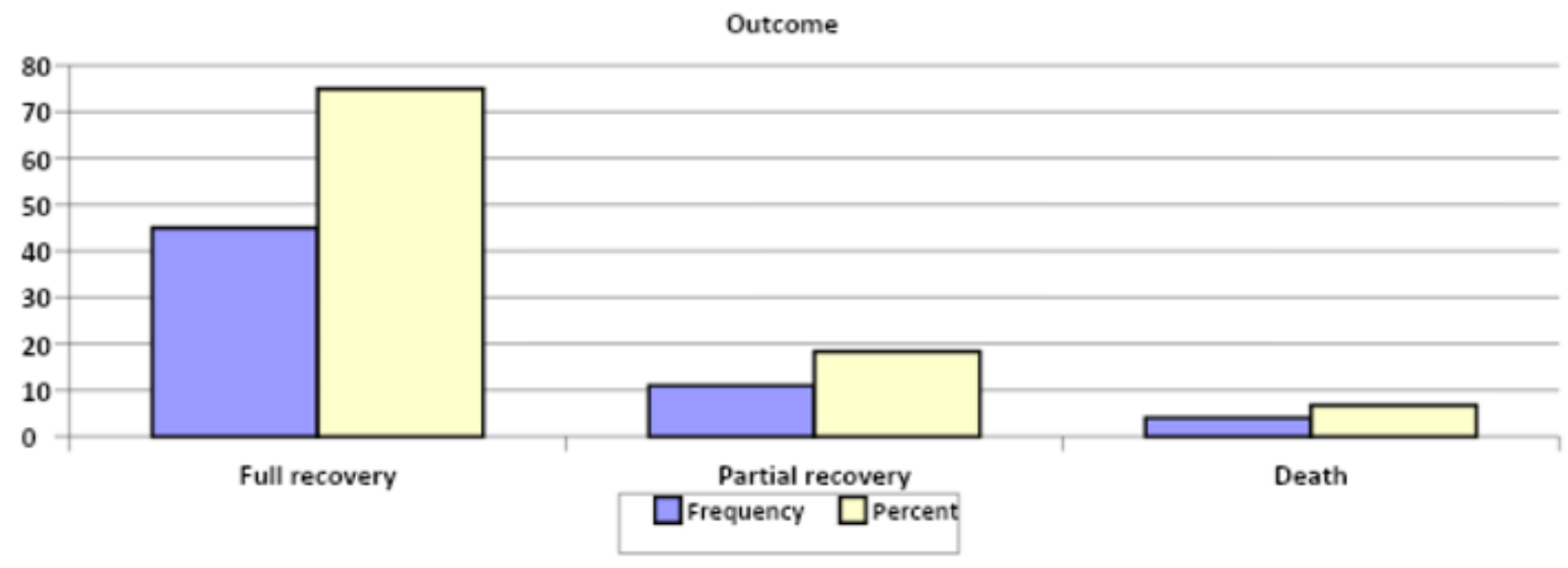

Figure 7

The distribution of the study participants according to the outcome $(n=60)$ 


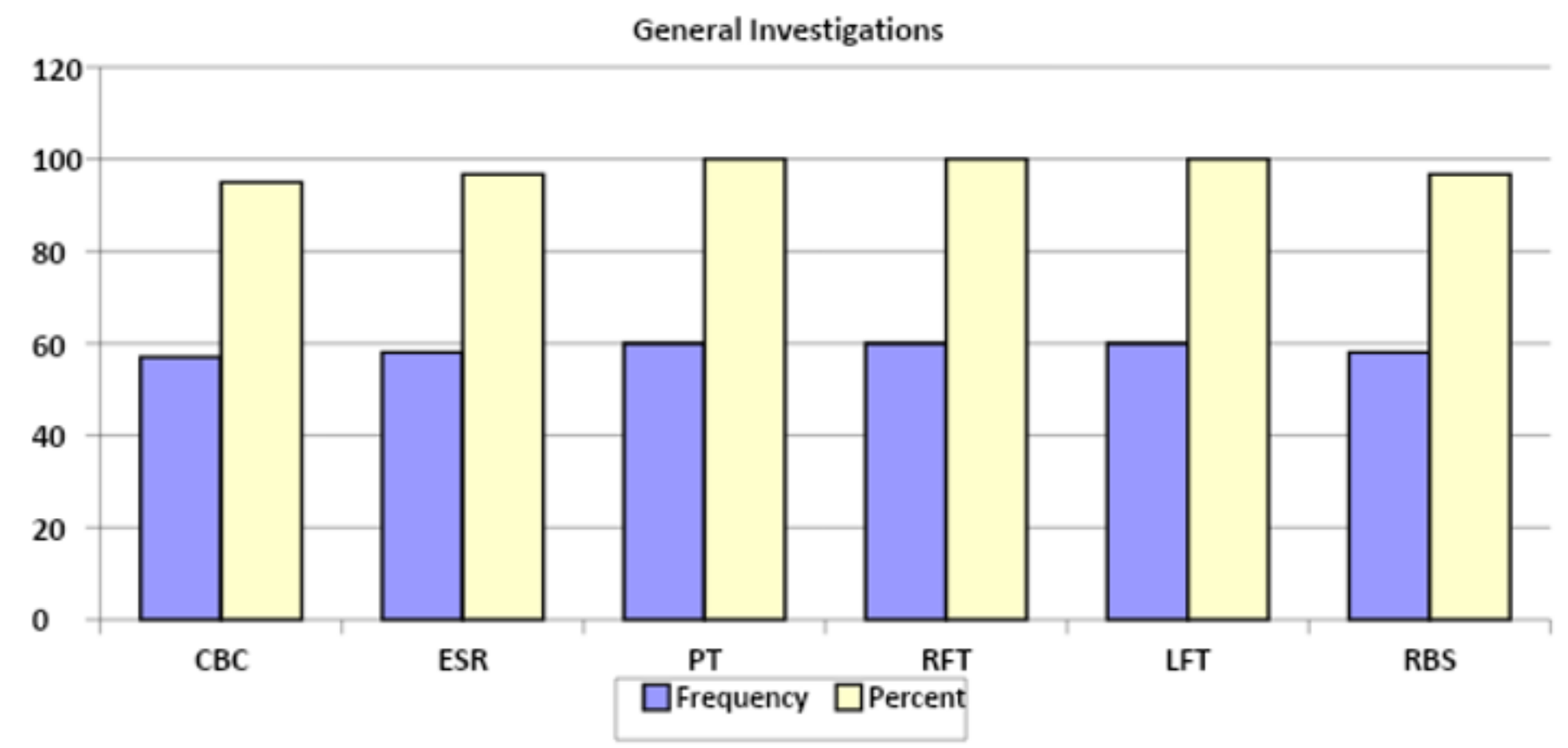

Figure 8

The distribution of the study participants according to the results of general investigations $(n=60)$

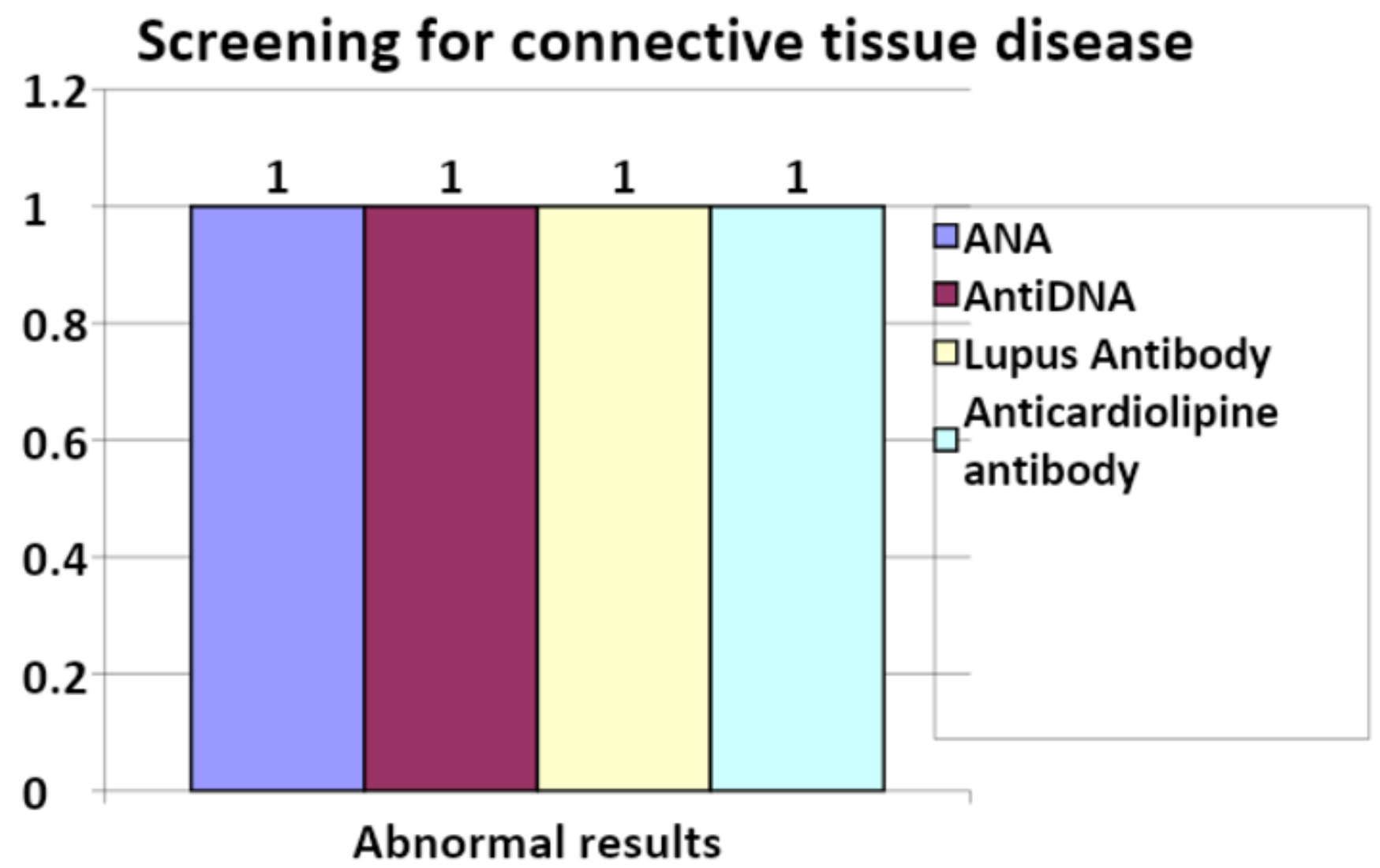

Figure 9 
The distribution of the study participants according to the results of connective tissue disease screening $(n=60)$

Thrombophilia screening

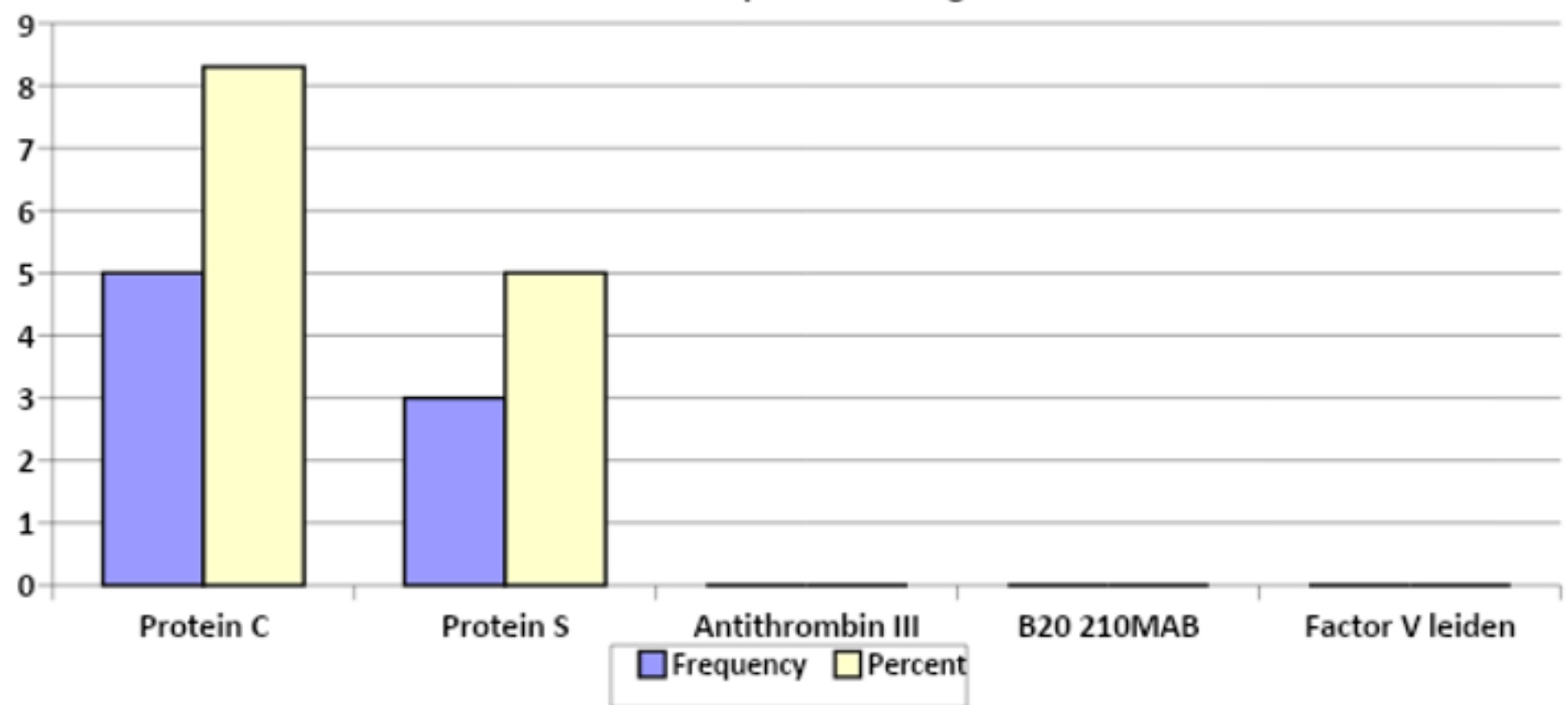

Figure 10

The distribution of the study participants according to the results of thrombophilia screening $(n=60)$ 


\section{Type of imaging study performed}

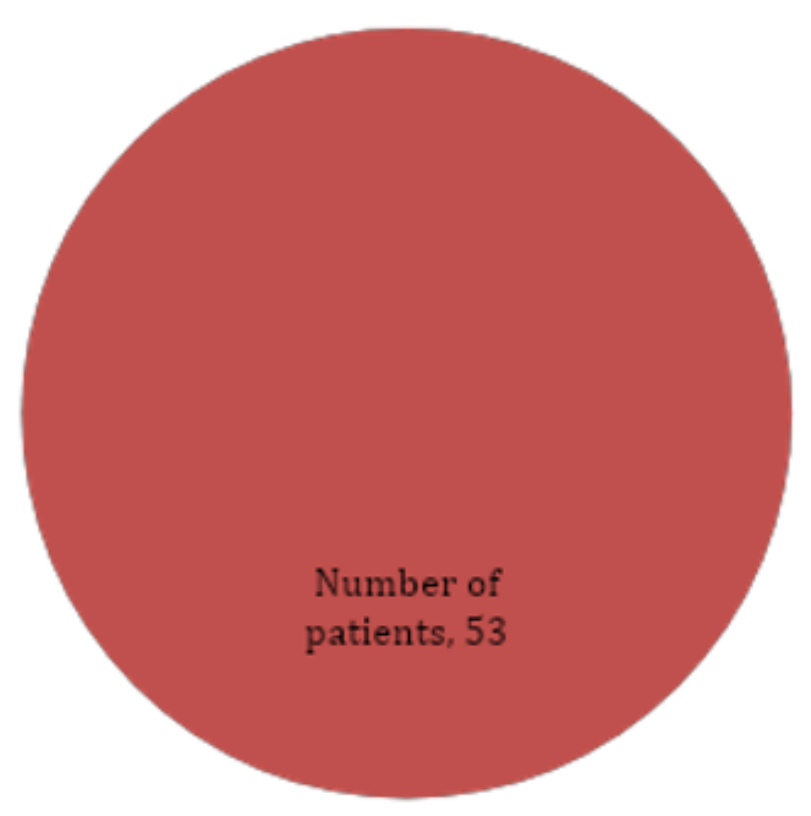

\section{Figure 11}

The distribution of the study participants according to the type of imaging study performed $(n=60)$

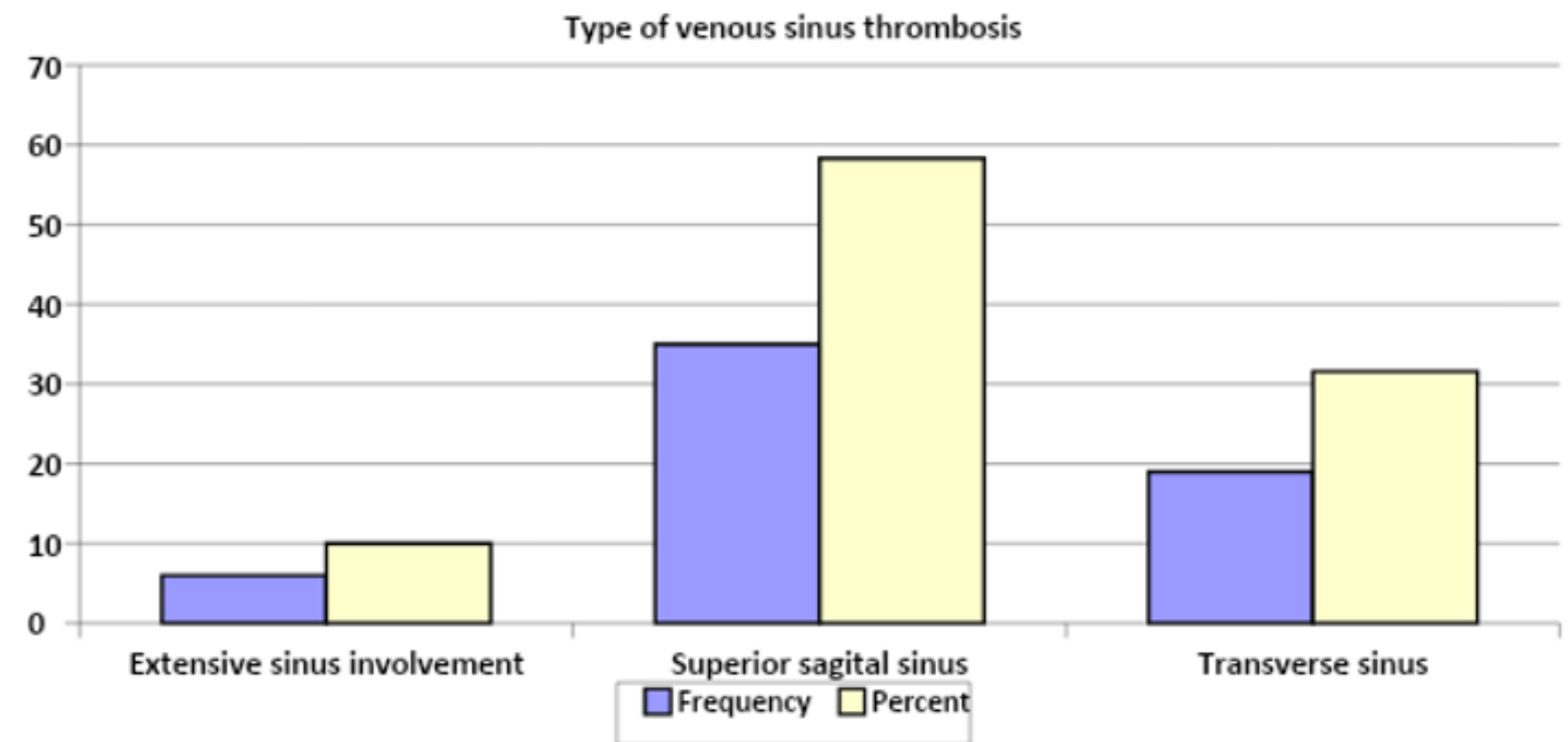


Figure 12

The distribution of the study participants according to the type of venous sinus thrombosis $(n=60)$

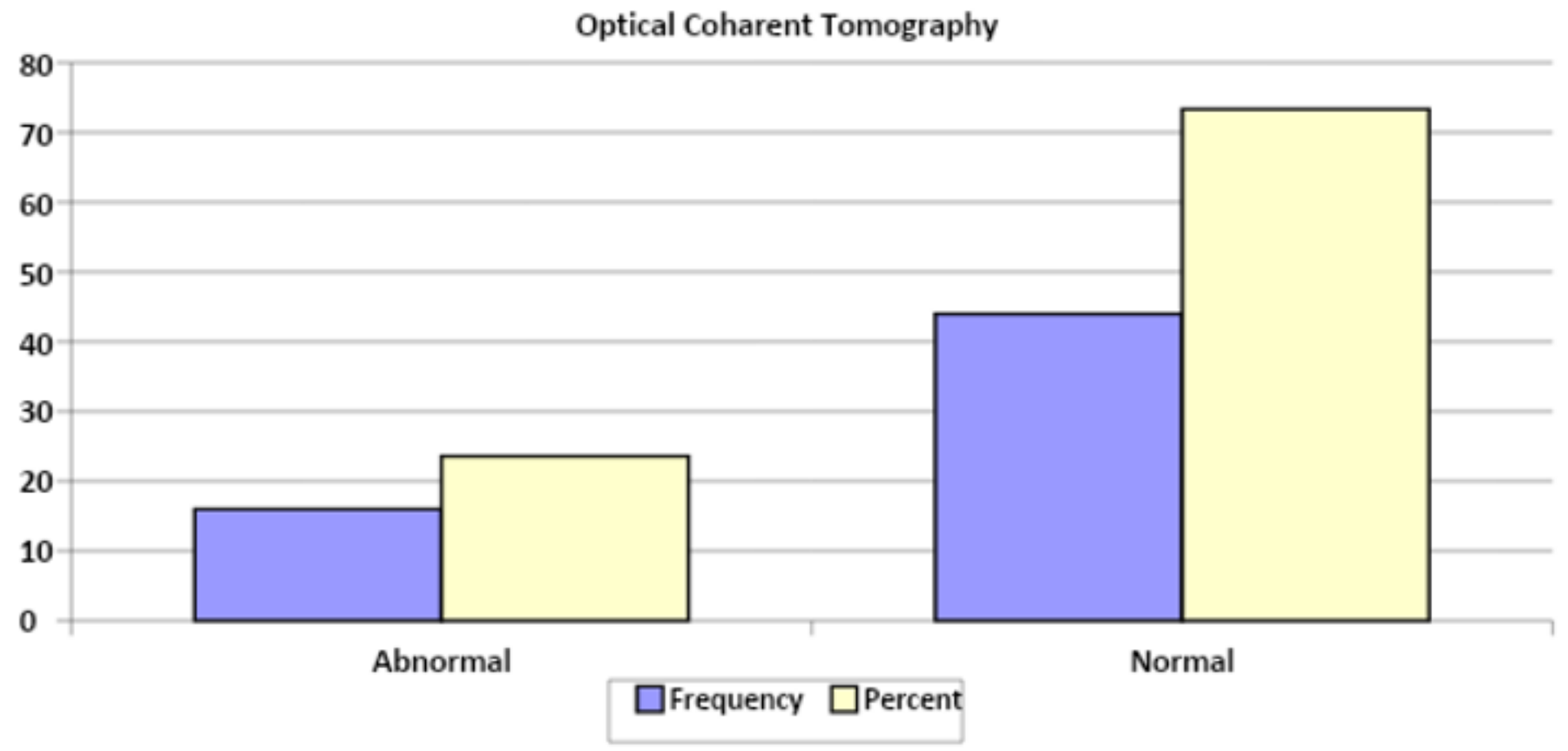

Figure 13

The distribution of the study participants according to the results of optical coherence tomography $(n=60)$ 

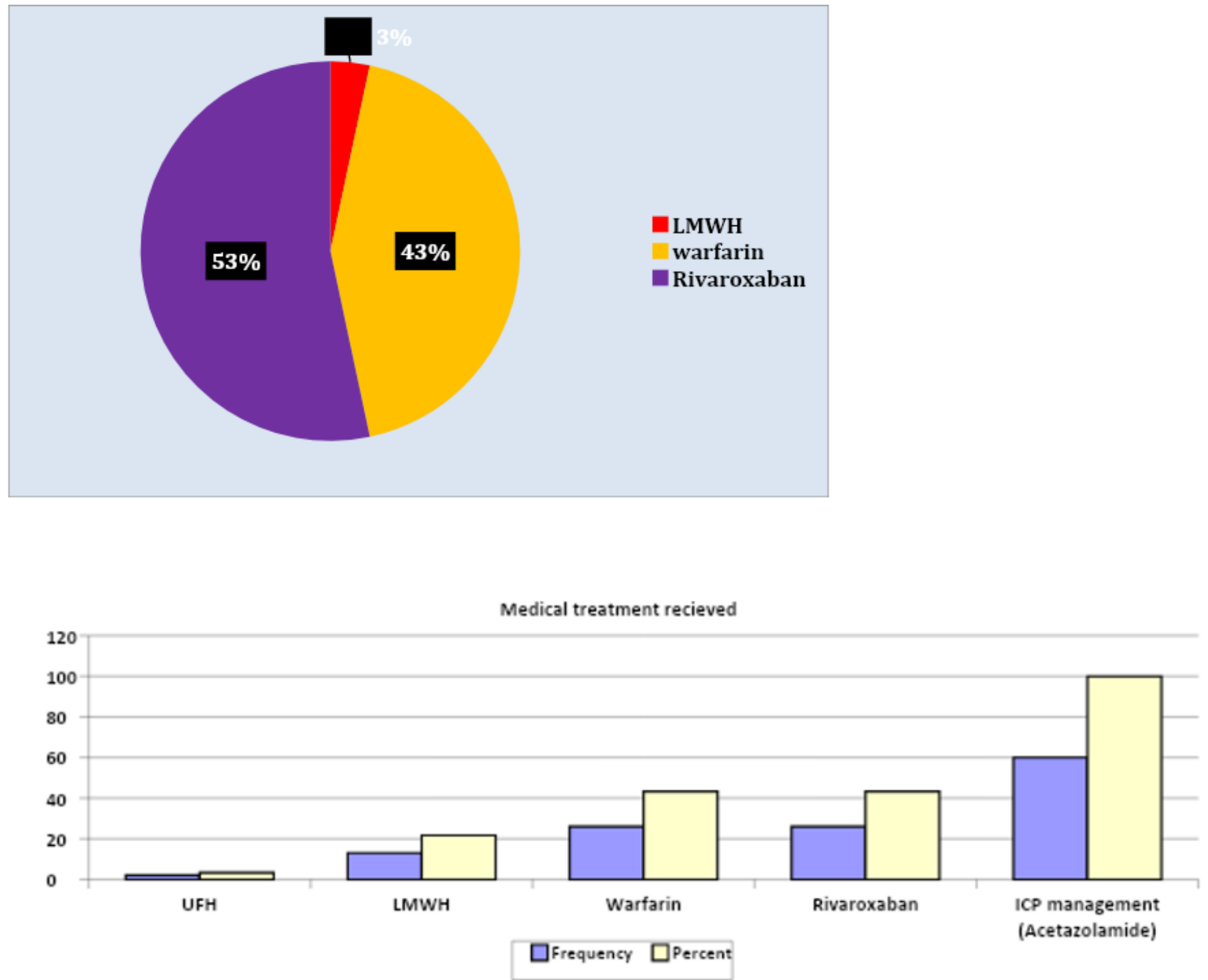

Figure 14

The distribution of the study participants according to the type of medical treatment received $(n=60)$ 

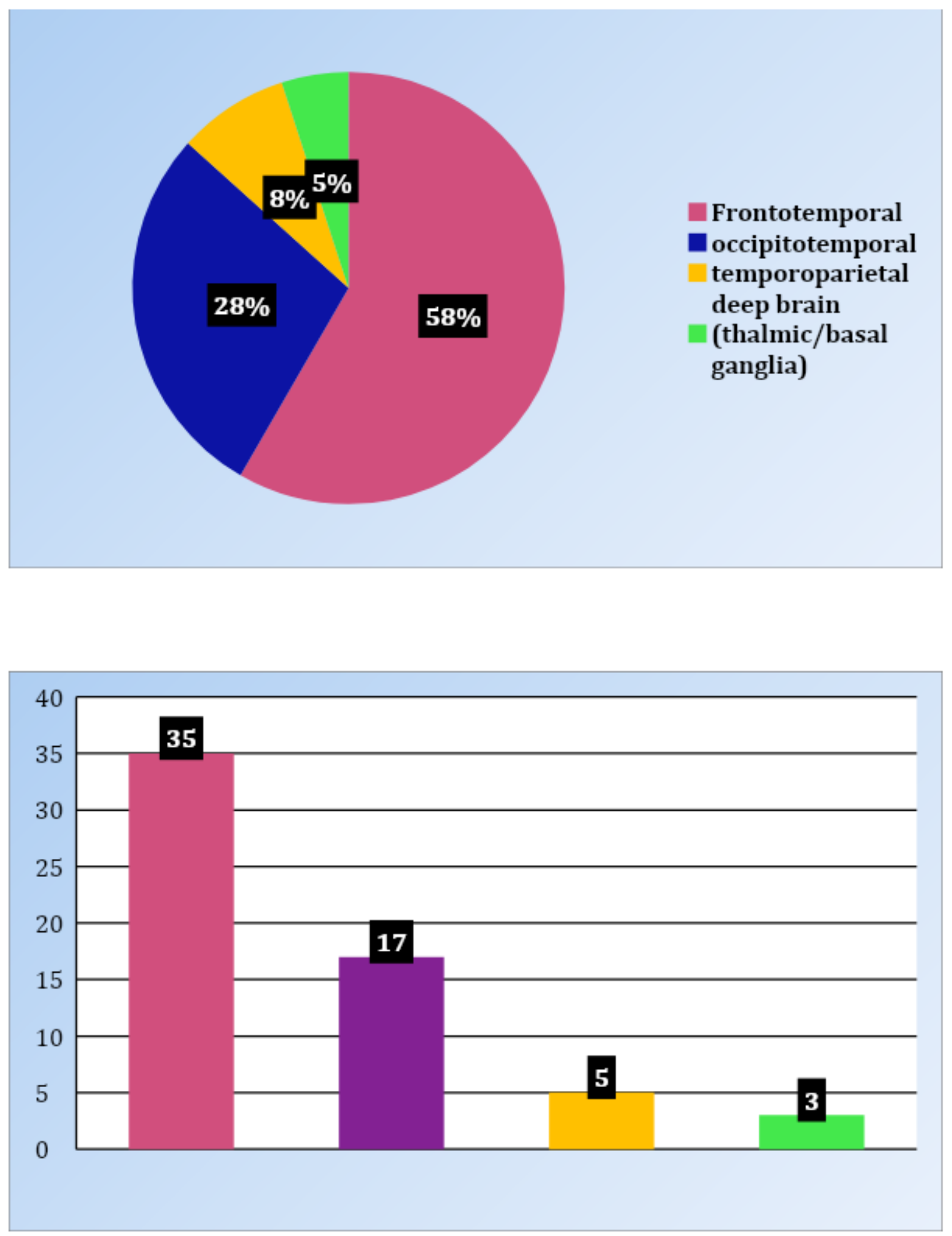

Figure 15

Site of lesions on MRI 


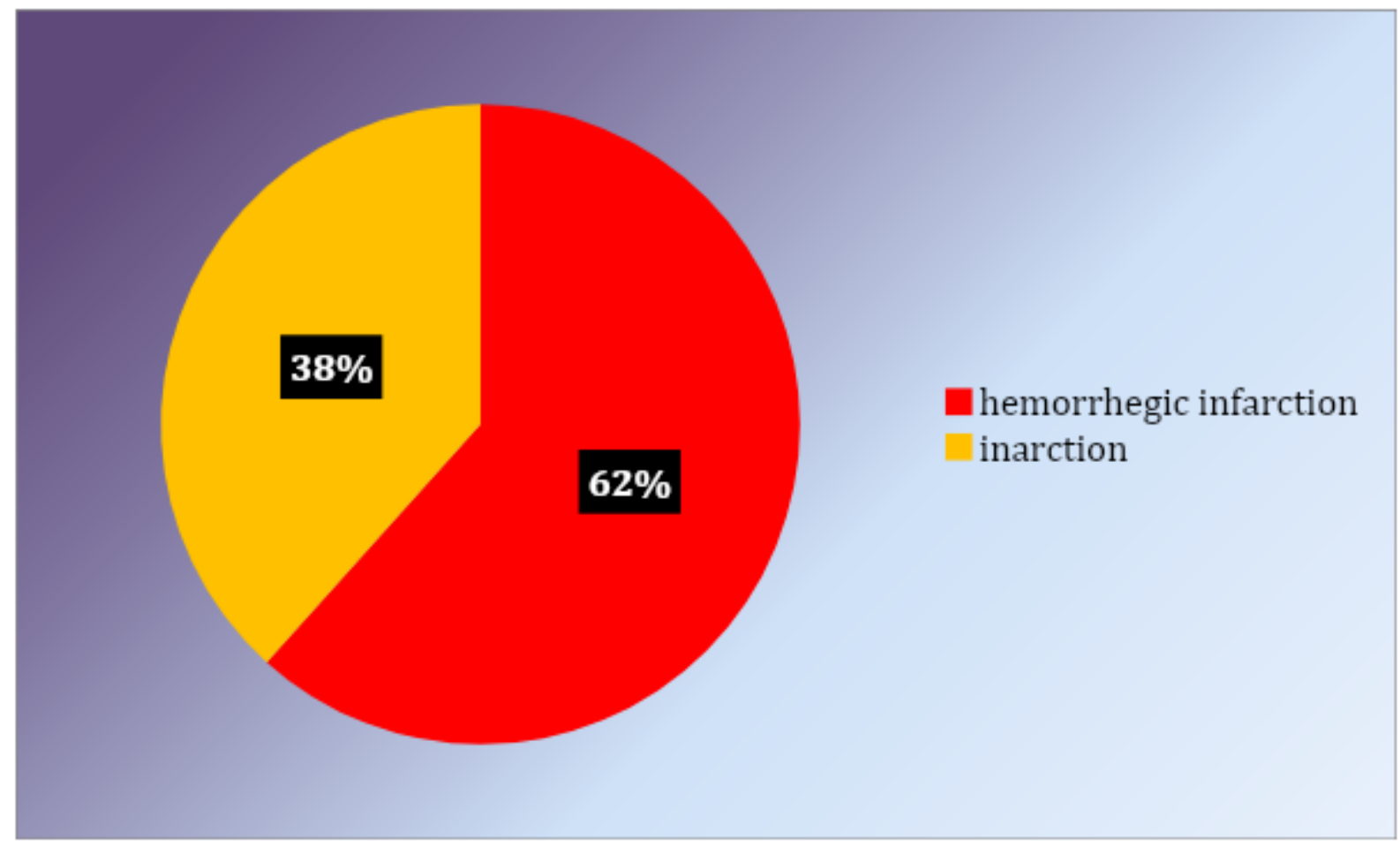

Figure 16

Types of lesions on MRI 

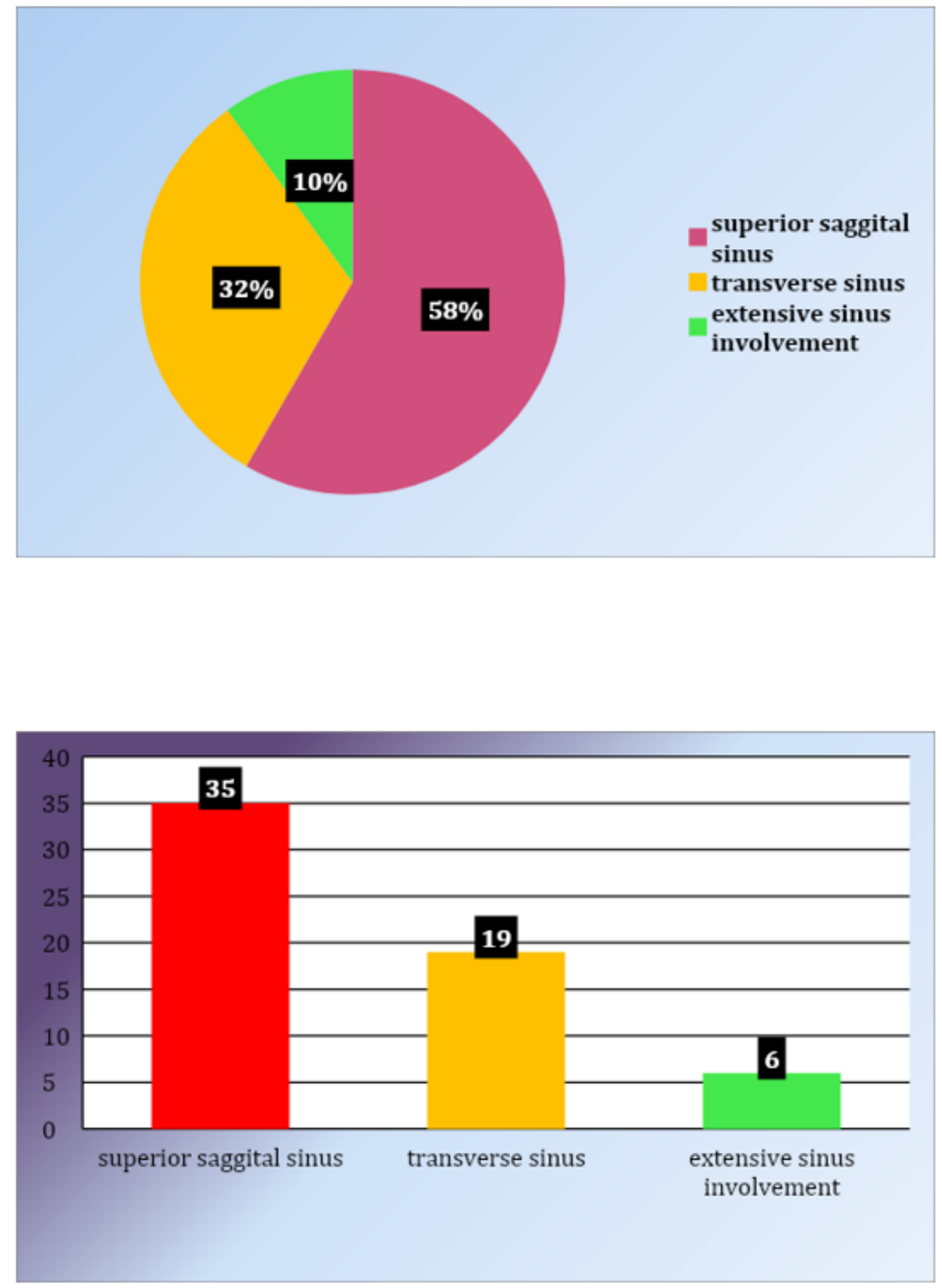

Figure 17

Sites of lesions on MRV

\section{Supplementary Files}

This is a list of supplementary files associated with this preprint. Click to download. 
- Appendix.docx

Page $42 / 42$ 